\title{
p38/MKP-1-regulated AKT coordinates macrophage transitions and resolution of inflammation during tissue repair
}

\author{
Eusebio Perdiguero, ' Pedro Sousa-Victor, ' Vanessa Ruiz-Bonilla, ${ }^{1}$ Mercè Jardí, ${ }^{1}$ Carme Caelles, ${ }^{2}$ Antonio L. Serrano, \\ and Pura Muñoz-Cánoves ${ }^{1,3}$ \\ 'Cell Biology Group, Department of Experimental and Health Sciences, Pompeu Fabra University, and Centro de Investigación Biomédica en Red de Enfermedades \\ Neurodegenerativas, 08003 Barcelona, Spain \\ 2Biomedical Research Institute, Barcelona Science Park, 08028 Barcelona, Spain \\ ${ }^{3}$ Institució Catalana de Recerca i Estudis Avançats, 08010 Barcelona, Spain
}

$\mathrm{R}$ epair of damaged tissue requires the coordinated action of inflammatory and tissue-specific cells to restore homeostasis, but the underlying regulatory mechanisms are poorly understood. In this paper, we report new roles for MKP-1 (mitogen-activated protein kinase [MAPK] phosphatase-1) in controlling macrophage phenotypic transitions necessary for appropriate muscle stem cell-dependent tissue repair. By restricting p38 MAPK activation, MKP-1 allows the early pro- to antiinflammatory macrophage transition and the later progression into a macrophage exhaustion-like state characterized by cytokine silencing, thereby permitting resolution of inflammation as tissue fully recovers. p38 hyperactivation in

\section{Introduction}

Tissue repair after damage is an evolutionary conserved process in which interactions between infiltrating inflammatory cells and resident stem cells must be finely coordinated if tissue integrity and homeostasis are to be restored. Perturbation of these interactions leads to unsuccessful healing (Gurtner et al., 2008; Eming et al., 2009; Soehnlein and Lindbom, 2010). Nonetheless, little is known about the molecular mechanisms controlling timely and efficient tissue repair.

Skeletal muscle regeneration after injury exemplifies the careful orchestration of inflammatory and tissue-specific stem

C. Caelles and A.L. Serrano contributed equally to this paper.

Correspondence to Pura Muñoz-Cánoves: pura.munoz@upf.edu

Abbreviations used in this paper: $B M$, bone marrow; $B M D M, B M-d e r i v e d$ macrophage; $\mathrm{CHX}$, cycloheximide; $C M$, conditioned media; CSA, cross-sectional area; CTX, cardiotoxin; DM, differentiation medium; eMHC, embryonic myosin heavy chain; GM, growth medium; H/E, hematoxylin/eosin; LNA, locked nucleic acid; LPS, lipopolysaccharide; MCK, muscle creatine kinase; miR, microRNA; PI3K, phosphatidylinositol 3-kinase; qPCR, quantitative real-time PCR; WT, wild type. macrophages lacking MKP-1 induced the expression of microRNA-21 (miR-21), which in turn reduced PTEN (phosphatase and tensin homologue) levels, thereby extending AKT activation. In the absence of MKP-1, p38induced AKT activity anticipated the acquisition of the antiinflammatory gene program and final cytokine silencing in macrophages, resulting in impaired tissue healing. Such defects were reversed by temporally controlled p38 inhibition. Conversely, miR-21-AKT interference altered homeostasis during tissue repair. This novel regulatory mechanism involving the appropriate balance of p38, MKP-1, miR-21, and AKT activities may have implications in chronic inflammatory degenerative diseases. cell responses. Macrophages are the major infiltrating inflammatory cells in damaged muscle and play an integral role in the successful healing process. At early stages after injury, macrophages phagocytose necrotic myofiber debris and provide the initial signals to activate muscle stem cell (satellite cell)-dependent tissue regeneration (Eming et al., 2009). Subsequently, the process of inflammation resolution requires specialized subsets of immune cells, such as antiinflammatory and alternatively activated macrophages, that have specific functional characteristics related to suppressing the initial proinflammatory response and promoting egress of inflammatory cells and the final stages of tissue replacement. Recent studies showed that infiltrating macrophages change their initial proinflammatory activation state (M1) to an antiinflammatory one (M2) during muscle regeneration

(C) 2011 Perdiguero et al. This article is distributed under the terms of an AttributionNoncommercial-Share Alike-No Mirror Sites license for the first six months after the publication date (see http://www.rupress.org/terms). After six months it is available under a Creative Commons License (Attribution-Noncommercial-Share Alike 3.0 Unported license, as described at http://creativecommons.org/licenses/by-nc-sa/3.0//. 
Figure 1. p38-MKP-1 balance is required for efficient skeletal muscle repair. (A) Number of F4/80-positive macrophages in WT muscle at the indicated times postinjury (P.I.) that were obtained by flow cytometry. Total number of cells per milligram of CTX-injured muscle tissue was calculated. (B) Phospho-p38- and phosphoc-Jun (as an indicator of activated JNK)-positive macrophages (P-p38 and P-clun, respectively) were counted in immunostained cryosections of gastrocnemius muscles obtained from WT mice 3,6 , and $10 \mathrm{~d}$ after injury (see pictures in Fig. S1 C). (C) Gene expression analysis by RT-PCR in isolated macrophage populations at the indicated times after injury. (D) As in $A$, number of F4/80-positive macrophages in WT and $M \mathrm{MP}^{-1} \mathrm{1}^{-1-}$ mice per milligram of injured muscle tissue. (E) As in B, phospho-p38- and phospho-c-Jun-positive macrophages from WT and $\mathrm{MKP}-1^{-1-}$ mice at the indicated times after injury (see pictures in Fig. S1 C). (F) Muscle cryosections were stained with an anti-eMHC antibody. Bar, $50 \mu \mathrm{m}$. (G) As in F, cryosections were stained with $H / E$, and the mean area of regenerating myofibers was calculated (see pictures in Fig. S1). Means \pm SEM of at least three experiments. ${ }^{* *}, \mathrm{P}<0.001 ;{ }^{* *}, \mathrm{P}<0.01$; $*, \mathrm{P}<0.05$.
A

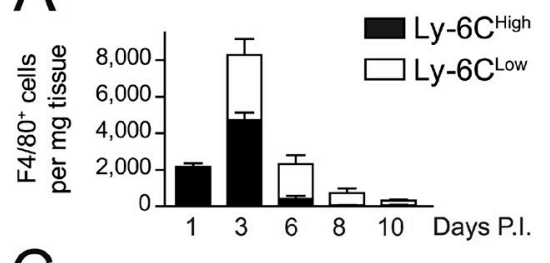

C $1 \frac{3}{6} \frac{6}{10}$ Days P.I
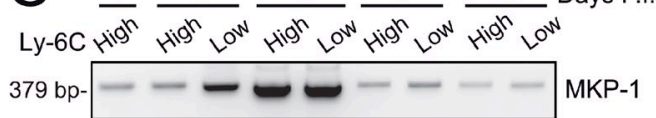

254 bp- $--\quad$ TNF $\alpha$

$231 \mathrm{bp}-(-\ldots$ IL-1 $\beta$
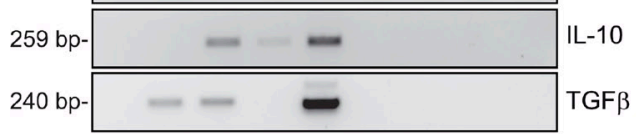

477 bp- $-\infty \quad$ p21

374 bp- $--------\infty$ CD16

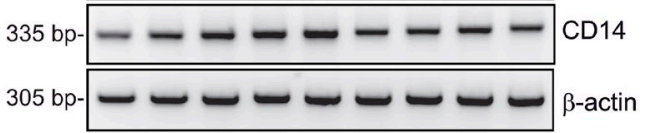

F

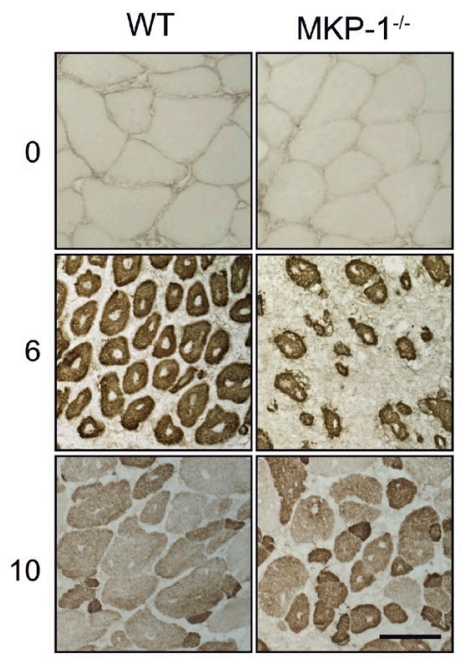

$\mathrm{eMHC}$

G

Days P.I.
B
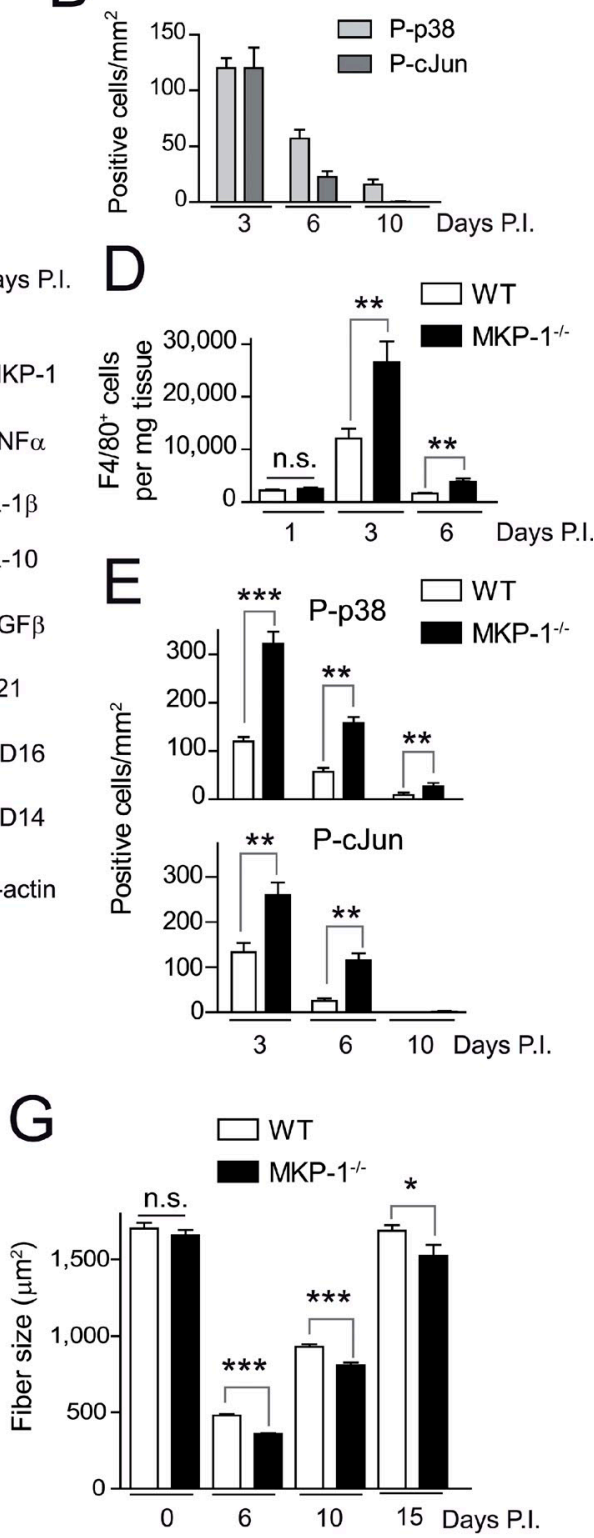

(Kokkola et al., 2005; Bianchi and Manfredi, 2007; Zhang and Mosser, 2008). The magnitude and duration of inflammation and, hence, of the linked MAPK activation state need to be tightly controlled because unrestrained inflammation underlies diverse forms of chronic diseases (Fukata et al., 2009). MKP-1 (MAPK phosphatase-1; archetype member of the MAPK phosphatase/dual specificity phosphatase family) controls the threshold and magnitude of MAPK activation by reversing MAPK phosphorylation (predominantly p38 MAPK; Wang and Liu, 2007; Li et al., 2009). Interestingly, MAPKs are known to induce MKP-1 gene transcription via a negative feedback loop as part of the induction of the antiinflammatory response to bacterial infection ( $\mathrm{Li}$ et al., 2001). This regulatory action seems also to account for the proposed positive and negative effects of MKP-1 on adipose and myogenic cells, as shown by 
gain- and loss-of-function studies in vitro and in vivo (Bennett and Tonks, 1997; Wu et al., 2006; Roth et al., 2009; Shi et al., 2010). Similarly, increases in TNF, IL-6 (interleukin-6), and IL-10 (interleukin-10) expression dependent on p38 activation, concomitant with enhanced induced NO synthase-NO and reduced arginase synthesis, have been proposed to underlie the exacerbated response to endotoxin challenge in mice genetically deficient in MKP-1 (Chi et al., 2006; Hammer et al., 2006; Wu et al., 2006; Zhao et al., 2006). Contrarily to the known role of MPK-1 on the inflammatory response to bacterial infection, its function in the control of macrophage transitions during tissue healing, from the initial inflammatory stage toward injury resolution, remains largely unknown.

In this study, we show that during muscle repair, the macrophage-intrinsic MKP-1-p38 balance critically regulates the timely transition of macrophages from a proinflammatory to antiinflammatory state and ultimate progression into an exhaustion-like state characterized by cessation of cytokine expression. Dysregulation of the sequential macrophage transitional states by loss of MKP-1 results in defective satellite cell functions and muscle tissue regeneration, whereas satellite cellintrinsic MKP-1 appears dispensable for the healing process. Finally, we uncover a novel mechanism connecting MKP-1 and phosphatidylinositol 3-kinase (PI3K)-AKT antiinflammatory activities through p38-regulated microRNA-21 (miR-21) expression during tissue repair.

\section{Results}

Different cytokine activation and silencing profiles of macrophage subsets during muscle regeneration parallel modifications of the p38-MKP-1 inflammatory pathway In response to injury, two subsets of macrophages are sequentially present in regenerating skeletal muscle. In acute injury models, damaged tissue first recruits Ly-6C $\mathrm{C}^{\text {high }}$ monocytes/ macrophages that exhibit a proinflammatory cytokine activation profile, whereas at later stages, macrophages within muscle switch their phenotype to become predominantly Ly-6C ${ }^{\text {low }}$, showing an antiinflammatory profile (Arnold et al., 2007). To determine whether the p38-MKP-1 inflammatory pathway is involved in this regenerative response to tissue injury, we characterized by cell sorting (FACS) the different macrophage populations present in muscle of wild-type (WT) mice (by cell number and activation profile) after injection of cardiotoxin (CTX) and analyzed their p38-MKP-1 activity over time. As shown in Fig. 1 A, proinflammatory Ly-6 $\mathrm{C}^{\text {high }}$ macrophages constituted the predominant population from day 1 to 3 , decreasing thereafter. At later time points, Ly-6C $\mathrm{C}^{\text {low }}$ macrophages were the most abundant, but their number was progressively reduced, paralleling tissue healing (Fig. $1 \mathrm{~A})$.

Muscle macrophages exhibited a peak of p38 and c-Jun (as a JNK pathway indicator) activation at $3 \mathrm{~d}$ of damage decreasing thereafter (Fig. $1 \mathrm{~B}$ ), whereas maximal MKP-1 expression was observed at $6 \mathrm{~d}$ (Fig. $1 \mathrm{C}$ ). Interestingly, p38 (but not JNK) remained active in macrophages at late stages after injury $(10 \mathrm{~d})$, suggesting a role of the p38 pathway in the resolution phase of inflammation. In agreement with a published study (Arnold et al., 2007), we observed that macrophages switched from proinflammatory ( $3 \mathrm{~d}$, expressing IL-1 $\beta$ and TNF) to antiinflammatory (6 d, expressing TGF $\beta$ and IL-10), but notably, we found that, at more advanced stages of regeneration ( 8 and $10 \mathrm{~d}$ after injury), muscle macrophages ceased the expression of both pro- and antiinflammatory cytokines (Fig. 1, A and C), turning into a "silenced" or "exhausted" state (i.e., this term implies an incapacity to produce either pro- or antiinflammatory cytokines). The modulated p38 activity and MKP-1 expression in muscle-infiltrating macrophages during repair (Fig. 1, B and C) suggested that the p38-MKP-1 balance may regulate macrophage transitions from pro- to antiinflammatory states and the acquisition of the cytokine-silencing phenotype.

Loss of MKP. 1 results in delayed and incomplete tissue recovery after injury To provide evidence for a direct regulatory role of p38-MKP-1 in inflammation after tissue injury, we used WT and MKP-1deficient (MKP-1 ${ }^{-l-}$ ) mice. MKP-1 ${ }^{-l-}$ mice have an exacerbated inflammatory response to infection, being hypersensitive to endotoxin treatment through unrestricted p38 activation in macrophages (Chi et al., 2006; Hammer et al., 2006; Wu et al., 2006; Zhao et al., 2006). We tested whether the immune response and tissue recovery processes would also be dysregulated in the absence of MKP-1 after acute injury. There was no genotypic difference in the number of circulating leukocytes in the peripheral blood $\left(2.7 \pm 0.9 \times 10^{3}\right.$ counts $/ \mu$ in WT mice vs. $3.0 \pm$ $1.3 \times 10^{3}$ counts/ $\mu \mathrm{l}$ in $\mathrm{MKP}-1^{-/-}$mice), and the number of infiltrating macrophages was similar in both mouse genotypes $1 \mathrm{~d}$ after injury (Fig. $1 \mathrm{D}$ ), suggesting that macrophage recruitment in injured tissue was not affected by MKP-1 loss. At subsequent stages after injury $(3,6$, and $10 \mathrm{~d})$ there was a significant increase in the number of macrophages in MKP-1 ${ }^{-1-}$ compared with WT muscle (Fig. 1 D and Fig. S1, A and B). MKP-1 ${ }^{-/-}$macrophages expressed active $\mathrm{p} 38$, as shown by serial immunohistochemical analyses with antiphospho-p38 and F4/80 antibodies (Fig. 1 E and Fig. S1 C). This was in agreement with the p38 activity profile observed in WT and MKP-1 ${ }^{-1-}$ macrophages subjected to proinflammatory stimulation in vitro (Fig. S1 D), strongly supporting that absence of MKP-1 in macrophages leads to unrestricted p38 activation and inflammation in damaged tissue. Tissue recovery and resolution of inflammation were impaired at 6 and $10 \mathrm{~d}$ after injury in MKP-1 $1^{-1-}$ mice compared with WT. Indeed, strongly expressing embryonic myosin heavy chain (eMHC)-positive myofibers were still present in $\mathrm{MKP}-1^{-/-}$ muscle, indicating ongoing de novo satellite cell-associated myogenesis at late stages after injury (Fig. 1 F). Moreover, the size of centrally nucleated fibers at 6 and $10 \mathrm{~d}$ after injury was reduced in the absence of MKP-1 (Fig. $1 \mathrm{G}$ and Fig. S1 E). This result was consistent with the persistent expression of satellite cell activation and differentiation markers (MyoD and Myogenin) in $\mathrm{MKP}-1^{-1-}$ muscle at $10 \mathrm{~d}$ after injury (Fig. S1 F), indicating deficient and delayed myofiber formation in $\mathrm{MKP}-1^{-1-}$ mice compared with WT. The inefficient muscle regeneration process in the absence of MKP-1 after CTX injection was reproduced with tissue laceration, an alternative experimental injury 
Figure 2. A dysregulated inflammation underlies the defective muscle regeneration of $\mathrm{MKPI}^{-1-}$ mice. (A) Effect of bone marrow (BM) transplantation. (left) Number of infiltrating macrophages after $B M$ transplantation at $10 \mathrm{~d}$ after injury. (right) CSA of regenerating myofibers in gastrocnemius muscles after $B M$ transplantation. (B) Frequency curves of myofiber size distribution in regenerating gastrocnemius muscles after BM transplantation. BM donors are enclosed in parentheses. Means \pm SEM of at least three experiments. $* * *, P<0.001$.
A

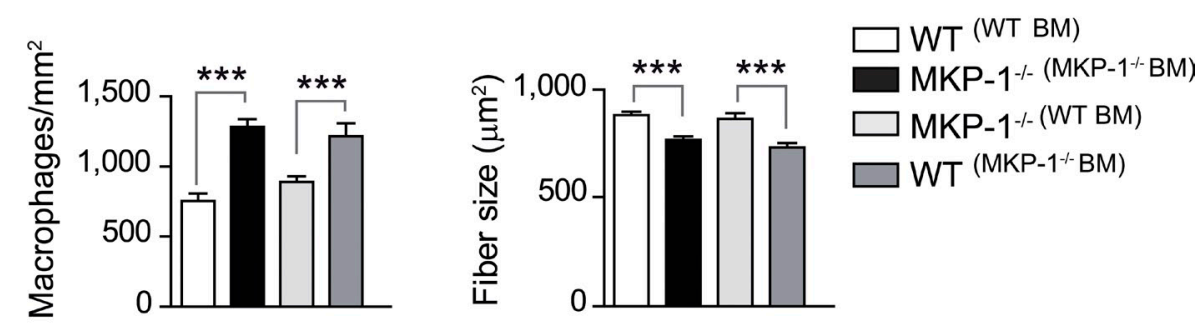

B

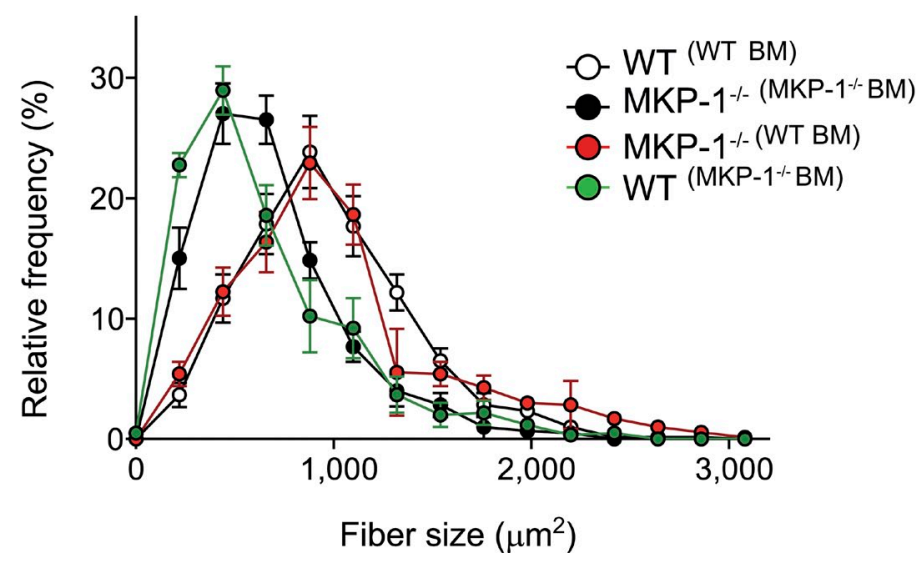

approach (Fig. S2 A; Menetrey et al., 1999). Because the initial number of satellite cells (identified by Pax7 [paired box protein 7] expression) and the cross-sectional area (CSA) of adult myofibers under basal (nonregenerating) conditions were identical in both genotypes (Fig. S2, B and C), MKP-1 loss appears to specifically inhibit muscle regeneration in the adult, being dispensable for muscle formation during development.

\section{Inflammatory MKP.1, rather than satellite cell-intrinsic MKP.1, is necessary for correct muscle tissue repair}

To clarify the relative contribution of inflammatory cell- versus satellite cell-intrinsic MKP-1 functions during muscle tissue repair, we undertook distinct experimental approaches. First, we evaluated whether transplantation of MKP-1-expressing bone marrow (BM) cells could restore muscle regeneration capacity in $\mathrm{MKP}-1^{-/-}$mice after injury. Transplantation of WT BM not only restored normal inflammation, but more importantly, it completely rescued the defective muscle regeneration in $\mathrm{MKP}-1^{-/-}$ mice (MKP-1 ${ }^{-/-}$(WT BM)) when compared with WT(MKP-1 ${ }^{-/-}$ $\mathrm{BM})$, as indicated by the decreased macrophage number and the increased CSA of regenerating fibers at $10 \mathrm{~d}$ after injury, respectively. This data demonstrates that $\mathrm{BM} / \mathrm{inflammatory}$ cell MKP-1 expression is critical for muscle repair (Fig. 2, $\mathrm{A}$ and $\mathrm{B})$. Second, to ascertain the intrinsic contribution of MKP-1 to satellite cell functions, we analyzed the satellite cell progeny of WT and MKP-1 ${ }^{-1-}$ single myofibers ex vivo. We found no difference in the number of myofiber-associated satellite cells expressing Pax7 at basal stage or $48 \mathrm{~h}$ and Myogenin at $72 \mathrm{~h}$ in both genotypes (Fig. S2 D). Furthermore, no differences were observed in the proliferation, differentiation, migration, and fusion rates of cultured WT and $\mathrm{MKP}-1^{-1-}$ satellite cells, correlating with a similar p38 activation pattern during the differentiation process (Fig. S2, E-I). Remarkably, addition of conditioned media (CM) from in vitro-activated primary MKP-1 $1^{-/-}$macrophages to cultured satellite cells increased their proliferation rate compared with $\mathrm{CM}$ from WT macrophages (Fig. S3 A). In contrast, CM from MKP-1 ${ }^{-/-}$macrophages, but not WT CM, reduced the extent of satellite cell differentiation (Fig. S3 B) and fusion (not depicted). Interestingly, these effects were reversed by specific neutralization of the cytokine TNF in MKP-1 $1^{-1-}$ CM (Fig. S3, A and B), suggesting that the inhibitory actions of $\mathrm{MKP}-1^{-/-}$macrophagesecreted factors on satellite cell functions may be exerted through proinflammatory cytokines.

\section{The early pro- to antiinflammatory macrophage phenotypic transition is regulated by the MKP.1-p38 balance during tissue repair}

We investigated whether the MKP-1-p38 pathway would be mechanistically implicated in the early transition of pro- to antiinflammatory macrophages. Unlike WT macrophages, FACSisolated MKP-1 ${ }^{-/-}$muscle macrophages (Fig. S3, C and D) of both Ly-6C ${ }^{\text {high }}$ and Ly-6C ${ }^{\text {low }}$ populations expressed high levels of antiinflammatory cytokines in addition to proinflammatory cytokines $3 \mathrm{~d}$ after injury (Fig. $3 \mathrm{~A}$ and Fig. S4 A). Because in WT macrophages, antiinflammatory cytokine expression was restricted to the Ly-6 $\mathrm{C}^{\text {low }}$ population in 6-d damaged muscle after injury (Fig. $3 \mathrm{~A}$, right), our results indicate that loss of MKP-1 anticipates the antiinflammatory gene program after tissue damage, resulting in a temporal overlap of pro- and antiinflammatory cytokine expression. 

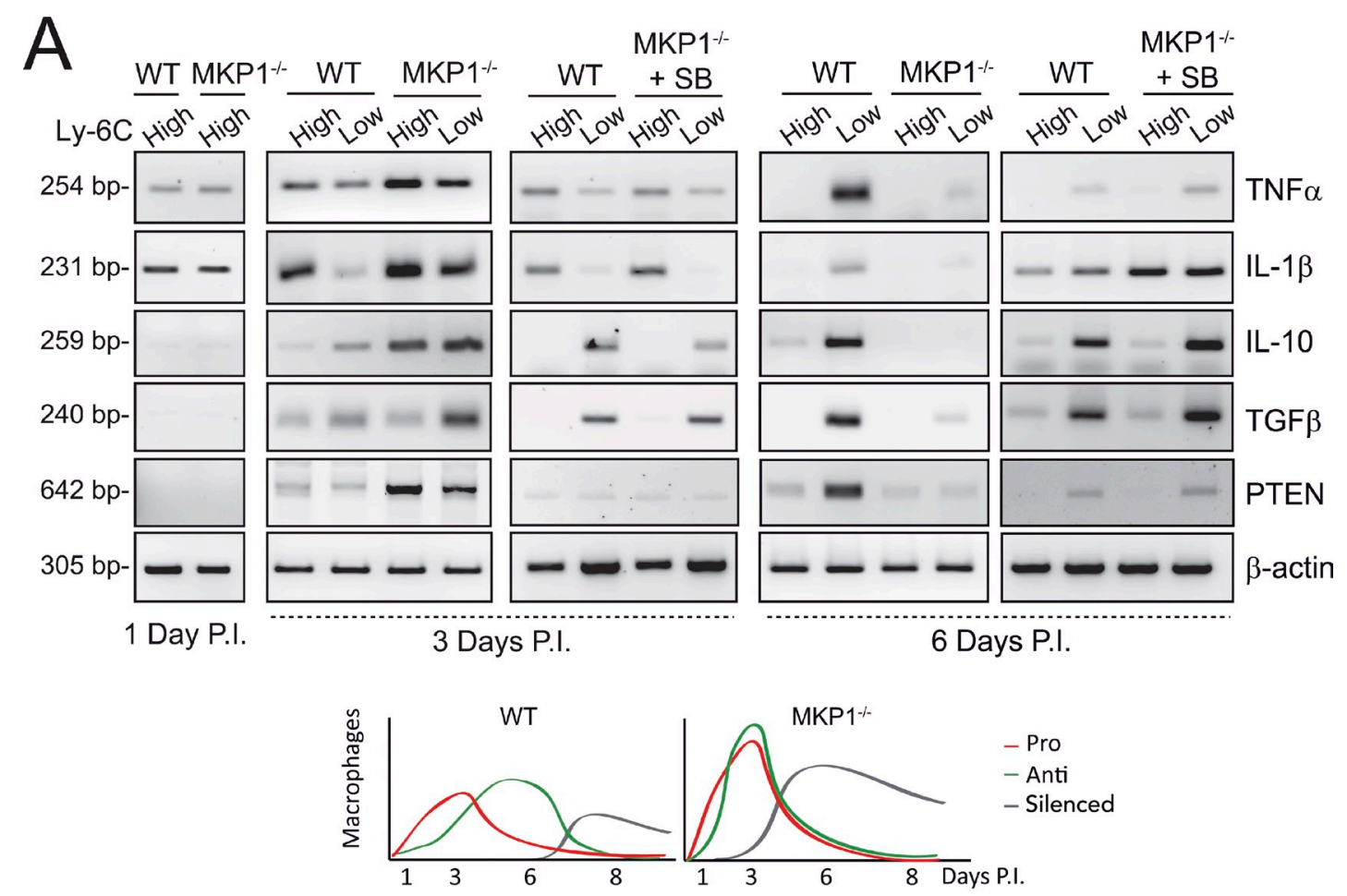

B

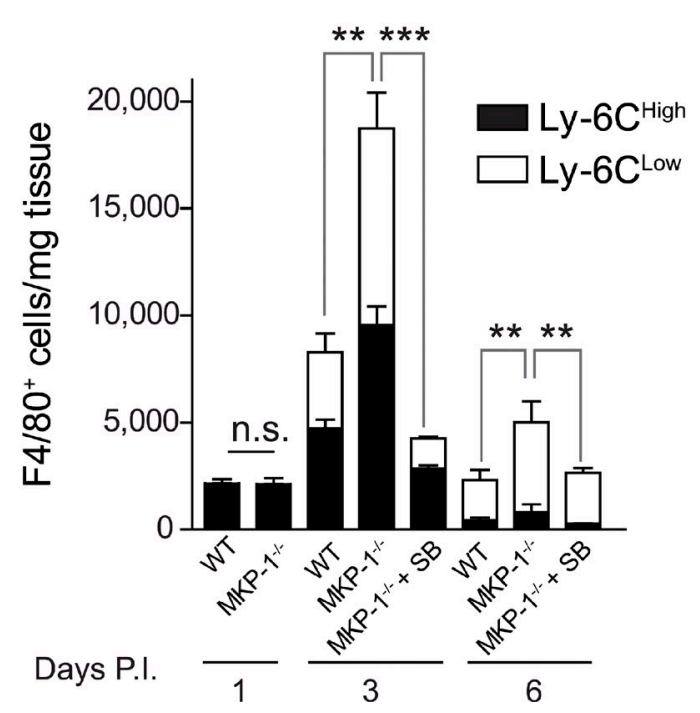

Figure 3. MKP-1 $1^{-/-}$macrophage population subsets display a mixed pro- and antiinflammatory phenotype at early stages of the muscle repair process and premature cytokine silencing at later stages caused by p38 hyperactivation. (A) Genes were analyzed by RT-PCR in isolated macrophage populations at 1, 3, and $6 \mathrm{~d}$ postinjury (P.I.). (bottom) A model of the temporal macrophage phenotypes in WT and MKP $1^{-1-}$ damaged muscles during repair. (B) F4/80-positive cells present in injured muscles of WT and MKP1 ${ }^{-1-}$ mice systemically treated with SB203580 (from 1 to 3 or 3 to $6 \mathrm{~d}$ ) were analyzed for Ly- $6 \mathrm{C}$ expression by flow cytometry. Total number of cells per milligram of injured muscle tissue was calculated. Means \pm SEM of at least three experiments. $* * *, P<0.001 ; * *, P<0.01$

Interestingly, p38 inhibition in vivo by SB203580 treatment of $\mathrm{MKP}-1^{-1-}$ damaged tissue restored both cell number and cytokine expression pattern of MKP-1 ${ }^{-1-}$ Ly- $6 \mathrm{C}^{\text {high }}$ and Ly- $6 \mathrm{C}^{\text {low }}$ macrophages at $3 \mathrm{~d}$ after injury, resembling those of WT macrophages (Fig. 3, A and B). It is worth mentioning that the ex vivo analysis of FACS-sorted macrophages within injured muscle has allowed us to specifically study the effect of p38 inhibition on macrophage cytokine production, hence bypassing potential effects of SB203580 on other cell types. Consistent with the in vivo results, in response to an inflammatory stimulus (either lipopolysaccharide [LPS] or recombinant HMGB1), cultured MKP-1 $1^{-/-}$macrophages simultaneously expressed high levels of pro- and antiinflammatory cytokines, coinciding with p38 hyperactivation in comparison with WT macrophages (Fig. S4 B and not depicted; Chi et al., 2006; Hammer et al., 2006; Wu et al., 2006; Zhao et al., 2006). Thus, during the early stages of tissue repair, MKP-1 controls both the overall magnitude of the inflammatory response as well as the timing of macrophage polarization via p38 down-regulation. 

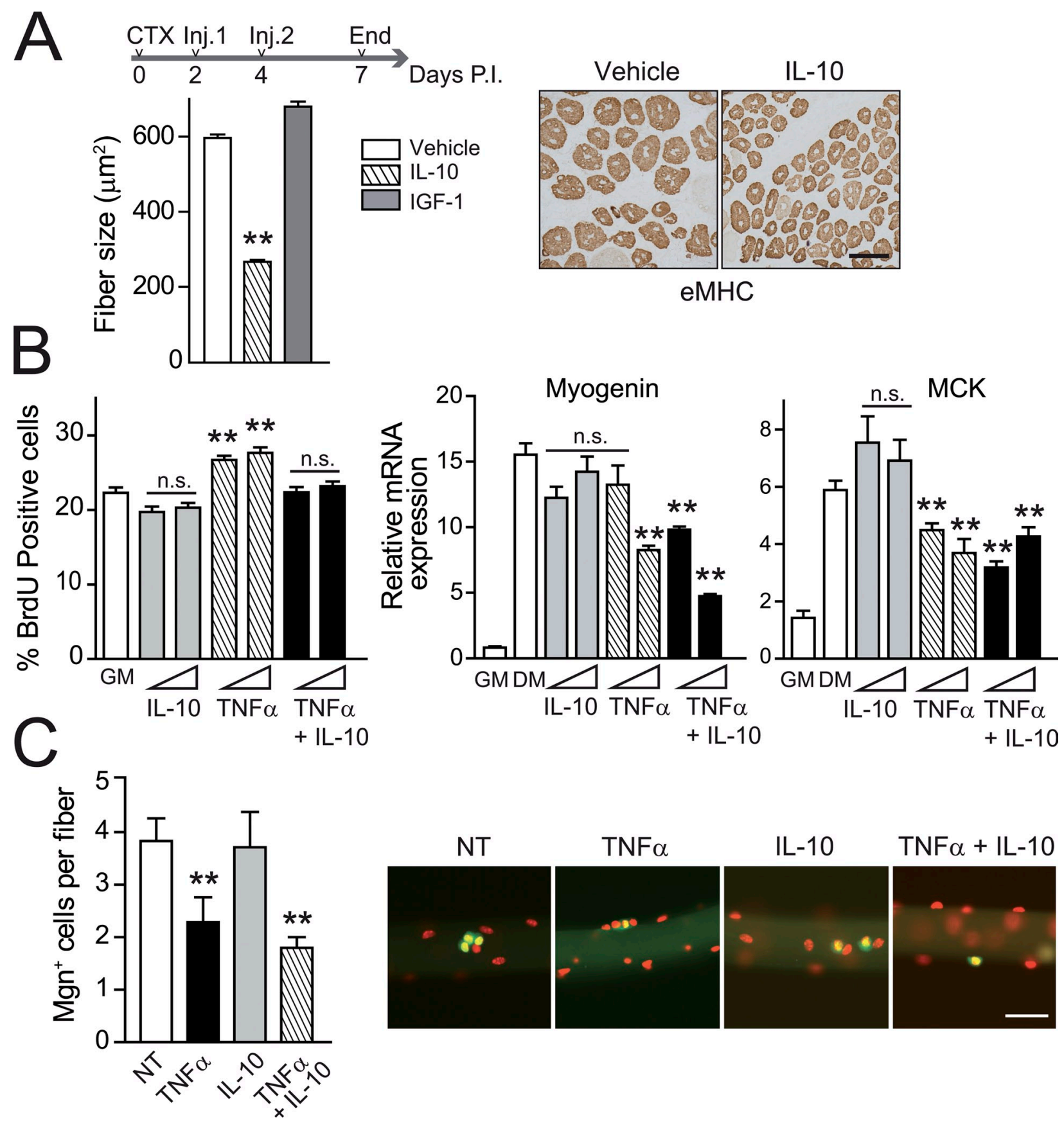

Figure 4. Forced premature expression of the antiinflammatory cytokine IL-10 impairs normal muscle repair. (A) Recombinant IL-10 or IGF-1 (Used as a control) was injected twice during the early stages of regeneration after CTX injury (Inj.). 7-d injured gastrocnemius muscles obtained from vehicle-treated mice or mice treated with IL-10 at $7 \mathrm{~d}$ postinjury (P.I.) were stained with an anti-eMHC antibody, and the mean area of regenerating myofibers was calculated. Bar, $50 \mu \mathrm{m}$. (B) WT satellite cells were cultured in GM for $24 \mathrm{~h}$ with $10 \mathrm{ng} / \mathrm{ml} \mathrm{IL-10,30} \mathrm{ng/ml} \mathrm{TNF,} \mathrm{or} \mathrm{a} \mathrm{combination} \mathrm{of} \mathrm{both.} \mathrm{(left)} \mathrm{Cells} \mathrm{were}$ incubated for $1 \mathrm{~h}$ with BrdU, and positive cells were quantified. (right) Satellite cells were cultured in DM for $48 \mathrm{~h}$ with the same treatment, and Myogenin and MCK expression was analyzed. (C) Single myofibers, with their associated satellite cells, isolated from mouse muscles were cultured ex vivo in GM as in B for $72 \mathrm{~h}$. Satellite cells were stained for Myogenin (Mgn; green) and TO-PRO-3 (red), and the number of positive cells in each fiber was counted. Bar, $100 \mu \mathrm{m}$. NT, nontreated cells. Means \pm SEM of at least three experiments. ${ }^{*}, \mathrm{P}<0.01$.

\section{Cytokine gene silencing during the}

resolution of inflammation at late stages of tissue recovery is controlled by the

MKP-1-p38 balance

Unexpectedly, we found that the mixed pro- and antiinflammatory phenotype of $\mathrm{MKP}-1^{-1-}$ macrophages present at $3 \mathrm{~d}$ after tissue injury was transient because in 6-d damaged $\mathrm{MKP}-1^{-1-}$ muscle, Ly-6C ${ }^{\text {low }}$ macrophages expressed almost undetectable levels of antiinflammatory (or proinflammatory) cytokines. This indicates that, during the repair process, loss of MKP-1 in muscle macrophages leads to premature silencing of cytokine expression (both pro- and antiinflammatory; Fig. 3 A, right), though other macrophage markers remained expressed (Fig. S4 A). We postulated that the premature expression of antiinflammatory 
cytokines in the absence of MKP-1 could underlie the premature silencing or exhaustion of the cytokine expression program in macrophages. Supporting this, addition of recombinant IL-10 and/or TGF $\beta$ was able to advance the decline of cytokine expression in WT macrophages in response to a proinflammatory stimulus (Fig. S4 C). The in vivo macrophage phenotype caused by MKP-1 loss was even more unexpected when considering the higher number of macrophages and the persistence of tissue damage in MKP-1 ${ }^{-1-}$ mice (compared with WT mice) $6 \mathrm{~d}$ after injury (Fig. $3 \mathrm{~B}$ and Fig. S1 E). Importantly, macrophages in SB203580-treated MKP-1 $1^{-1-}$ tissue regained an antiinflammatory cytokine expression profile similar to WT macrophages, as indicated after FACS analysis (Fig. 3 A, right). Thus, as tissue repair advances, the p38-MKP-1 balance controls, first, the pro- to antiinflammatory macrophage polarization and, later, the transition to an exhausted state with cessation of cytokine expression.

\section{Interference with the ordered expression of pro- and antiinflammatory cytokines alters the course of tissue repair}

To test whether the premature expression of antiinflammatory cytokines in $\mathrm{MKP}-1^{-/-}$muscle macrophages (overlapping with that of proinflammatory cytokines) might contribute in part to the inefficient repair of $\mathrm{MKP}-1^{-1-}$ muscles, we tried to recapitulate this mixed inflammatory status in injured WT muscle and analyzed the consequences on new myofiber growth. Local delivery of IL-10 early after WT muscle injury ( 2 and $4 \mathrm{~d}$ after CTX injection, when proinflammatory cytokine expression is predominant) reduced the CSA of newly forming fibers measured at $7 \mathrm{~d}$ after injury compared with saline-treated contralateral damaged muscle (Fig. 4 A). As a control, no reduction of myofiber CSA was observed after IGF-1 (insulin-like growth factor 1) administration. These in vivo results were complemented with two ex vivo satellite cell-based models. Treatment with IL-10 was found to reverse the proproliferative effect of TNF on cultured satellite cells, as shown by BrdU incorporation (Fig. 4 B, left) and cell counting (after $5 \mathrm{~d}$ in culture, TNF increased the number of satellite cells by $25 \pm 3.5 \%$ over WT numbers), whereas TNF/IL-10 co-stimulation did not have a proproliferative effect. Conversely, the differentiation-promoting effect of IL-10 on satellite cells, as shown by enhanced Myogenin and muscle creatine kinase (MCK) expression, was abolished by cotreatment with TNF (Fig. 4 B, right). Finally, in isolated single myofibers from adult mouse muscle, the simultaneous addition of TNF and IL-10 for $72 \mathrm{~h}$ reduced the number of Myogenin ${ }^{+}$ satellite cells per fiber (Fig. 4 C). Thus, timely, sequential expression of pro- and antiinflammatory cytokines produced by specific macrophage subsets appears critical to allow, first, satellite cell proliferation and, later, their differentiation and fusion into myofibers. Consistent with this, premature initiation of the antiinflammatory cytokine program in injured WT muscle with IL-10 (mimicking MKP-1 loss) led to inefficient tissue healing.

Next, we aimed to investigate further the direct requirement of $\mathrm{p} 38$ to regulate this pro- to antiinflammatory macrophage transition. SB203580 treatment of WT macrophages (initiated at the same time or after endotoxin stimulation) reduced both the early proinflammatory (IL-1 $\beta$ and TNF) and the late antiinflammatory (TGF $\beta$ and IL-10) waves of cytokine expression (Fig. 5 A). Similar results were obtained when HMGB1 was used as an initiating stimulus (unpublished results). In addition, the late IL-10 and TGF $\beta$ mRNA induction in these cells was blocked by actinomycin D and by cycloheximide (CHX; Fig. 5 B), suggesting the requirement of a newly synthesized protein intermediate for antiinflammatory cytokine expression. When the function of IL-1 $\beta$ was blocked with an IL- $1 \beta$ neutralizing antibody, the late LPS-dependent IL-10 and TGF $\beta$ induction in macrophages was significantly reduced (Fig. 5 C). Conversely, recombinant IL-1 $\beta$ was able to induce the expression of both antiinflammatory cytokines (in the absence of LPS; Fig. 5 C). Interestingly, this latter effect did not require de novo protein synthesis but was dependent on p38 activity, as indicated from combined treatments with recombinant IL- $1 \beta / \mathrm{CHX}$ and IL- $1 \beta$ / SB203580, respectively (unpublished data). This data strongly supports the direct action of IL-1 $\beta$ on antiinflammatory gene expression mediated by $\mathrm{p} 38$. Hence, in response to an initial insult, the early macrophage proinflammatory response (i.e., IL-1 $\beta$ and likely also TNF production) is required for the activation of the subsequent antiinflammatory response (i.e., IL-10 and TGF $\beta$ production), which in turn may help to terminate the overall inflammatory reaction. Collectively, this indicates that the p38-MKP-1-controlled transition of macrophages from a pro- to an antiinflammatory phenotype appears critical, first, to counter the early proinflammatory cytokine environment in the damaged tissue, and, second, to directly stimulate satellite cell-mediated differentiation and fusion to newly forming myofibers, thus ensuring timely and successful tissue regeneration.

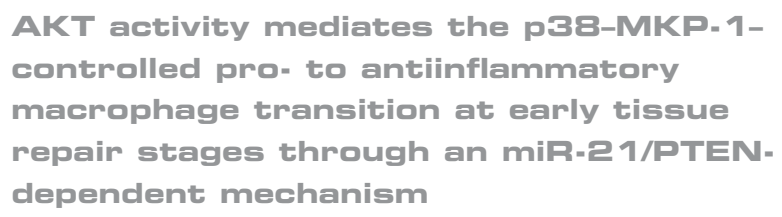

To further understand mechanistically how p38-MKP-1 regulate these macrophage inflammatory transitions, we checked the AKT activation status of WT and $\mathrm{MKP}-1^{-/-}$macrophages in damaged muscle because an antiinflammatory role for AKT in response to LPS has been previously suggested (Guha and Mackman, 2002; Luyendyk et al., 2008). AKT activity was reduced in macrophages at early phases of tissue regeneration, coinciding with the mixed pro- and antiinflammatory profile, and in more advanced stages of the repair process, AKT activity remained higher in $\mathrm{MKP}^{-/-}$macrophages (Fig. $6 \mathrm{~A}$ and Fig. S4 D). This higher activity correlated with loss of pro- and antiinflammatory cytokine gene expression in the absence of MKP-1 and suggested the likely requirement of AKT inhibition for pro- to antiinflammatory cytokine switching and subsequent cytokine silencing in WT macrophage at advanced stages of tissue repair.

First, to clarify whether AKT activity could control the timing of macrophage polarization, WT mice were treated with the PI3K-AKT inhibitor wortmannin $3 \mathrm{~d}$ after injury, and the 


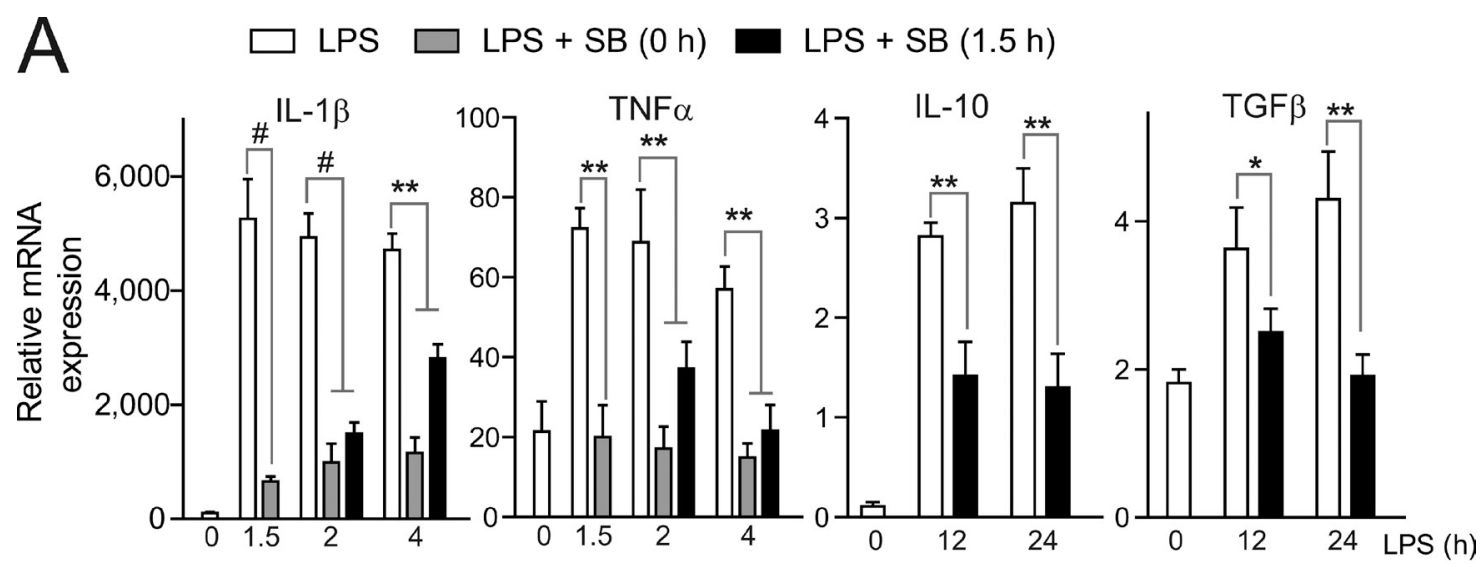

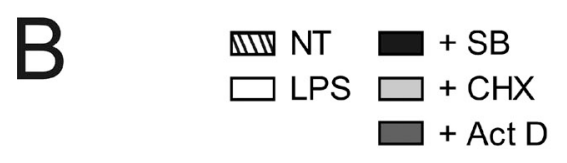

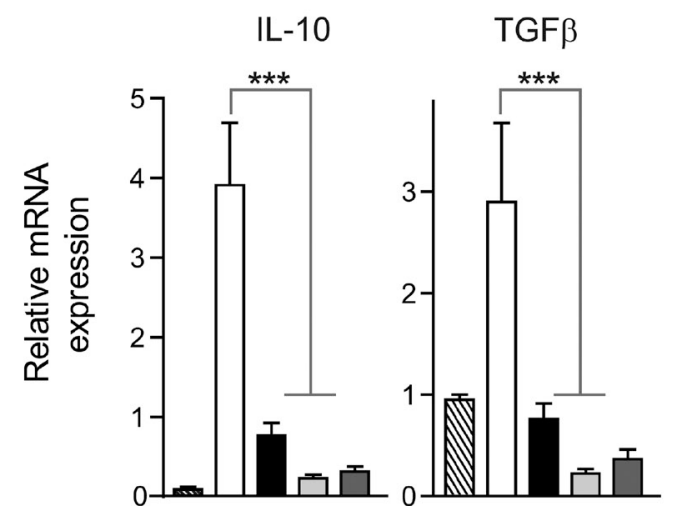

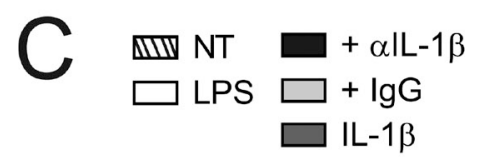

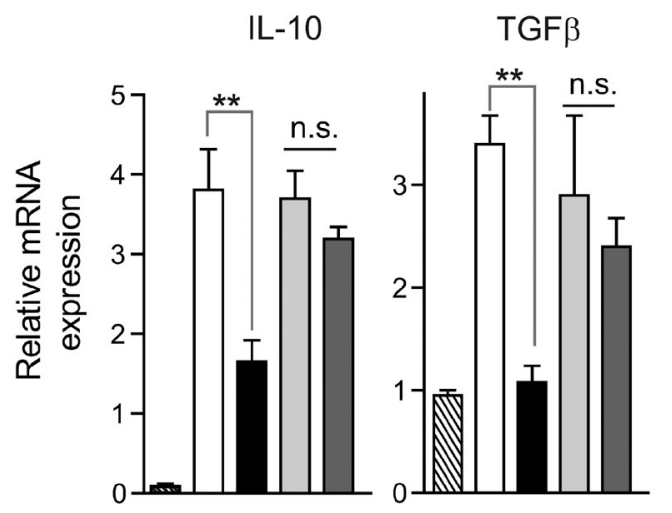

Figure 5. Early p38-induced IL-1 $\beta$ stimulates the later expression of the antiinflammatory cytokines IL-10 and TGF $\beta$ in cultured macrophages. (A) Primary macrophages were cultured in vitro and stimulated with LPS. At the time of stimulation, or after $1.5 \mathrm{~h}$, cells were treated or not treated with SB203580 (SB) for the indicated times. Comparative qPCR analysis. NT, nontreated cells. (B) Primary macrophages were treated with LPS \pm SB203580, cycloheximide $(\mathrm{CHX})$, or actinomycin $\mathrm{D}(\mathrm{Act} \mathrm{D})$. (C) As in B, cells were treated with an IL-1 $\beta$ neutralizing antibody, control lgG antibody, or recombinant IL-1 $\beta$ for $24 \mathrm{~h}$ (in this case, in the absence of LPS). Means \pm SEM of at least three experiments. ${ }^{* * *}$ or ${ }^{\#}, \mathrm{P}<0.001 ;{ }^{* *}, \mathrm{P}<0.01 ;{ }^{*}, \mathrm{P}<0.05$.

macrophage number and activation status was analyzed $3 \mathrm{~d}$ later. Wortmannin delivery extended the expression of proinflammatory cytokines till $6 \mathrm{~d}$ after injury while concomitantly enhancing antiinflammatory cytokine expression (Fig. 6 B and Fig. S5 A). Thus, transient PI3K-AKT inhibition in WT macrophages at early/mid stages of repair phenocopied the mixed cytokine activation status of MKP-1 $1^{-/-}$macrophages observed shortly after injury. Consistent with this, we found that in cultured MKP-1 $1^{-/-}$ macrophages, the increased and mixed cytokine expression pattern in response to a proinflammatory stimulus coincided with enhanced AKT activation (Fig. $6 \mathrm{C}$ and Fig. S4 B).

We next wanted to elucidate how the MKP-1-p38 balance controls AKT activation in macrophages. Recently, the tumor-associated miR-21 was found to be up-regulated in RAW264.7 cells stimulated with LPS (Sheedy et al., 2010). Because the AKT-inactivating phosphatase PTEN is a bona fide target of miR-21 (Meng et al., 2007), we tested whether the miR-21/PTEN axis could be operating in macrophages. Consistent with enhanced AKT activation, PTEN levels were lower in FACS-isolated MKP-1 ${ }^{-1-}$ macrophages compared with WT at $6 \mathrm{~d}$ after injury (Fig. $3 \mathrm{~A}$, right), coinciding with an increased expression of miR-21 (Fig. 6 D). Notably, this was reversed by SB203580 delivery in vivo (Fig. 3 A), suggesting that dysregulated miR-21 expression by hyperactivated p38 leads to unrestrained AKT activity in the absence of MKP-1, which might underlie the enhanced presence of MKP-1 $1^{-/-}$macrophages at advanced tissue repair stages. Confirming this hypothesis, forced overexpression of miR-21 (with a mimic miR-21), but not scrambled oligonucleotide miR (oligo-miR), in WT muscle macrophages (Fig. $6 \mathrm{E}$ and Fig. S5 B) resulted in an increased number of antiinflammatory macrophages at a later injury stage. Furthermore, inhibition of miR-21 with a specific antagonist miR (ant-miR-21) in endotoxin-treated macrophages attenuated the decline in cytokine expression over time while decreasing AKT activation (Fig. $6 \mathrm{~F}$ and Fig. S5, C and D). Conversely, miR-21 overexpression with the mimic miR-21 reduced expression of both pro- and antiinflammatory cytokines (Fig. $6 \mathrm{G}$ ), supporting the concept that miR-21 is an effector of p38 in modulating macrophage transition tissue persistence via AKT activation. To directly prove that $\mathrm{p} 38$ regulates miR-21 expression, macrophages were infected with a retrovirus expressing 
A

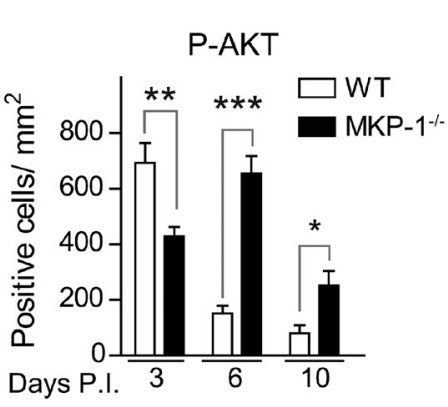

C
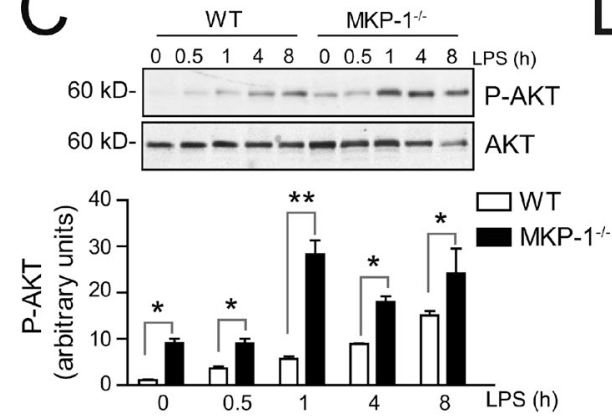

B

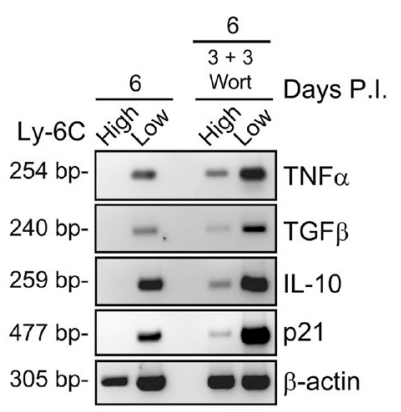

$D$

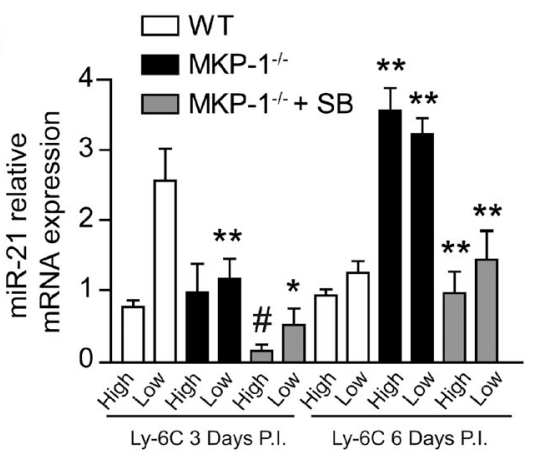

E
G
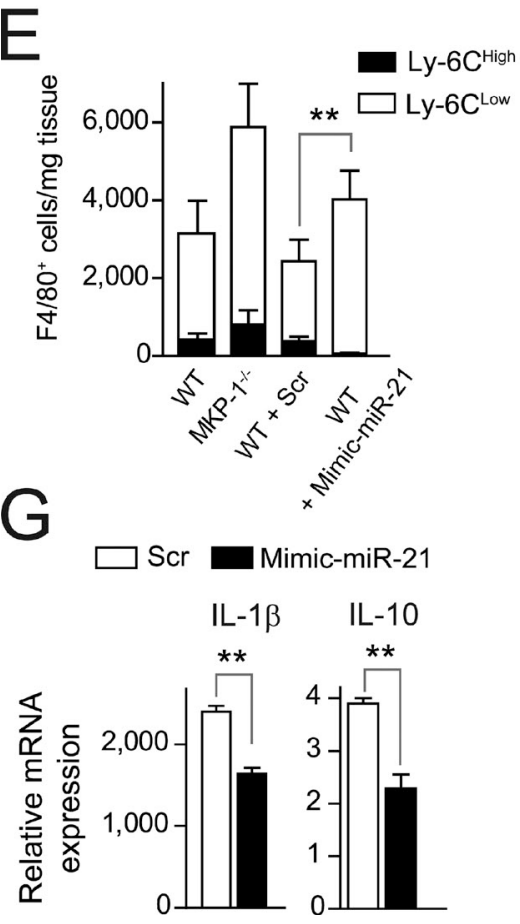

Mimic-miR-21
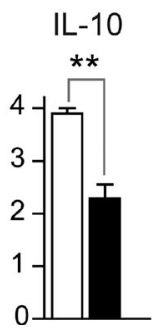
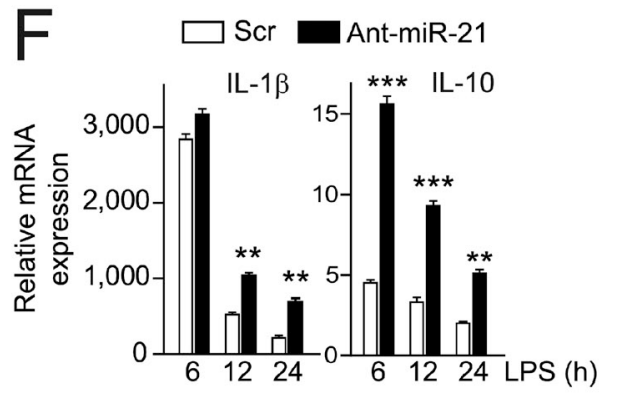

$\mathrm{H}$

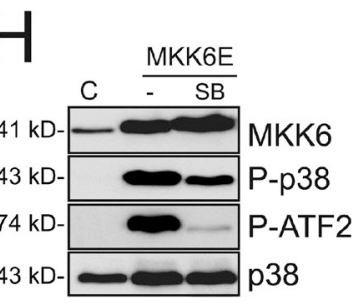

Figure 6. Increased AKT activity in MKP-1 -/- $^{-}$ macrophages is controlled by p38-induced miR-2 1 expression. (A) Phospho-AKT (P-AKT)positive macrophages were counted from immunostained serial cryosections of gastrocnemius muscles obtained from WT and MKP-1 $1^{-1-}$ mice postinjury (P.I.; see pictures in Fig. S5 D). (B) Gene expression analysis by RT-PCR in FACS-isolated macrophage populations at $6 \mathrm{~d}$ after injury from mice treated with wortmannin or vehicle for the preceding $3 \mathrm{~d}$. (C) WT and MKP-1 $1^{-1-}$ BM macrophages were stimulated with LPS at the indicated times. Western blotting analysis using phospho-AKT and AKT antibodies. (D) Expression of miR-2 1 was analyzed by qPCR in isolated macrophage populations at 3 and $6 \mathrm{~d}$ after injury from WT and $\mathrm{MP}-1^{-1-}$ mice or WT mice treated with SB203580 (SB). (E) Total number of macrophages per milligram of muscle at $6 \mathrm{~d}$ after injury. Muscles were injected with scrambled or mimic miR-21 oligonucleotides at $3 \mathrm{~d}$ after injury. (F) Primary macrophages were transfected with scrambled or ant-miR-2 1 oligonucleotides and stimulated with LPS for the indicated times; IL-1 $\beta$ or IL-1 0 expression analysis. (G) As in F, primary macrophages were transfected with scrambled (Scr) or miR-21 mimic oligonucleotides. (H) Primary macrophages infected with a retrovirus expressing MKK6E or an empty retrovirus $(C$, control), in the absence or presence of SB203580, were analyzed for MKK6, phospho-p38 (P-p38), phospho-ATF2 (P-ATF2), and p38 expression by Western blotting (left) or for miR-21 mRNA expression by $\mathrm{qPCR}$ analysis (right). Means \pm SEM of at least three experiments. ${ }^{*}$ or $* * *, P<0.001$; ${ }^{*}, \mathrm{P}<0.01 ;{ }^{*}, \mathrm{P}<0.05$ a constitutively active form of MKK6 (MKK6E), the p38activating kinase (Cuenda et al., 1996), As shown in Fig. $6 \mathrm{H}$, MKK6E-activated p38 could directly induce miR-21 gene expression in macrophages in the absence of stimuli, and this induction was blunted by SB203580 treatment, likely through a previously described AP-1 binding site within the miR-21 gene promoter (Qi et al., 2009; Roy et al., 2009; Ribas and Lupold, 2010). In support of this possibility, overexpression of a form of ATF2 not phosphorylatable by p38, but not WT ATF2 (a well-known substrate of p38 that can bind to AP-1 sites), also abrogated the MKK6E/p38-mediated induction of miR-21 (Fig. S5 E).

\section{Cessation of cytokine expression required for resolution of inflammation at late stages of tissue recovery depends on AKT activity}

As shown in Fig. 1, p38 remained active in macrophages at late stages after injury when tissue is almost fully recovered $(10 \mathrm{~d})$, coinciding with a decline in MKP-1 expression, sustained activity of AKT, and cessation of the expression of both pro- and antiinflammatory cytokine expression. Furthermore, compared with WT mice, AKT activity was also higher in $\mathrm{MKP}^{-/-}$macrophages at $6 \mathrm{~d}$ (and also at $10 \mathrm{~d}$ after injury; Fig. $6 \mathrm{~A}$ and Fig. S4 D), correlating with its unscheduled cytokine silencing (Fig. 1 C), 


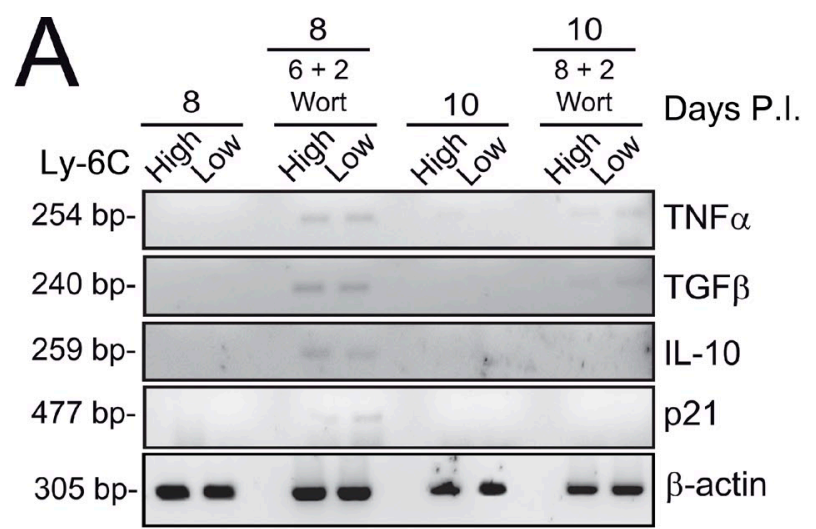

B
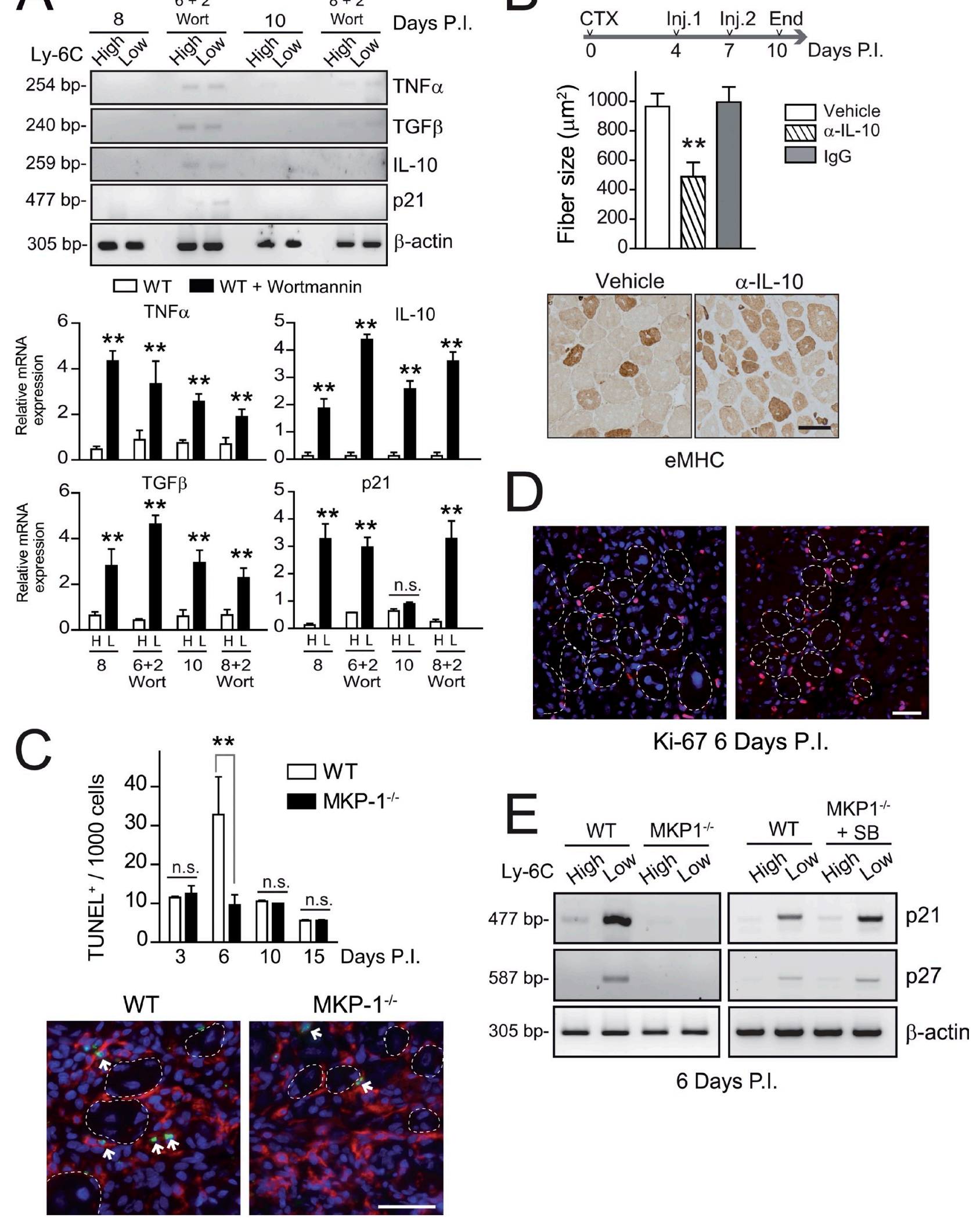

F4/80 TUNEL 6 Days P.I.

Figure 7. Transient PI3K-AKT inhibition in WT macrophages maintains cytokine expression and prevents cytokine silencing at late stages of the tissue repair process. (A) Gene analysis by RT-PCR in FACS-isolated macrophage populations at 8 and $10 \mathrm{~d}$ after injury from mice treated with wortmannin (Wort) or vehicle for the preceding $2 \mathrm{~d}$. (B) Anti-IL-10 neutralizing antibody was injected twice during the later stages of muscle regeneration after CTX 
thus suggesting that AKT, in addition to regulating the earlier pro- to antiinflammatory cytokine switching, might also be required for the final cytokine silencing in WT macrophages at advanced stages of tissue repair. To test this possibility, WT mice were transiently treated with wortmannin at 6 or $8 \mathrm{~d}$ after injury, and the macrophage number and activation status was analyzed 2 d later. Although macrophages in vehicle-treated WT muscles presented a silenced cytokine profile (i.e., no expression of pro- or antiinflammatory cytokines), the transient wortmannin treatment prevented full cytokine silencing, as indicated by residual expression of both pro- and antiinflammatory cytokines (Fig. 7 A). Because transient SB2013580 treatment prevented premature cytokine silencing of $\mathrm{MKP}-1^{-1-}$ macrophages at $6 \mathrm{~d}$ after injury (Fig. $3 \mathrm{~A}$ ), these results taken together strongly support a role for MKP-1 (through p38 neutralization and subsequent AKT down-regulation) in controlling sequential cytokine activation-silencing transitions in macrophages during tissue repair by restraining AKT activation.

Prompted by these results, we hypothesized that antiinflammatory cytokine neutralization at advanced tissue repair stages in WT muscles will provide an environment similar to that of $\mathrm{MKP}-1^{-1-}$ muscles, which could affect the final tissue repair course. Confirming this possibility, delivery of an IL-10 neutralizing antibody, at intermediate-advanced stages after injury (4 and $7 \mathrm{~d}$ after CTX injection), reduced the size of regenerating fibers analyzed $10 \mathrm{~d}$ after injury compared with IgG-treated contralateral damaged muscle (Fig. 7 B), indicating that premature neutralization of antiinflammatory cytokines has deleterious consequences on the active growth of newly formed myofibers at advanced stages of tissue healing.

Finally, FACS analysis and immunohistochemistry showed a higher number of $\mathrm{MKP}-1^{-/-}$macrophages in injured muscle at any time point of the repair process, which could be reduced by SB203580 treatment (Fig. 3 B). Based on the major recognized role of the PI3K-AKT pathway in cell proliferation/ survival, we reasoned that the altered AKT activation pattern in MKP-1 ${ }^{-1-}$ macrophages might also change their growth/ survival properties, thereby affecting macrophage persistence in injured muscle. To demonstrate this, we performed F4/80 and TUNEL double immunostaining (Fig. $7 \mathrm{C}$ ) and found that damaged $\mathrm{MKP}-1^{-/-}$muscles indeed had a reduced number of apoptotic macrophages compared with WT muscle, correlating with an increased presence of Ki-67-positive cells (Fig. 7 D). In agreement with these data, FACS-isolated $\mathrm{MKP}-1^{-1-}$ macrophages were found to express lower levels of the cell cycle inhibitors p21 and p27 than WT macrophages (Fig. 7 E), suggesting that enhanced survival and proliferation rates could account for the increased macrophage presence in $\mathrm{MKP}-1^{-1-}$ damaged muscle, and this could be rescued by SB203580 treatment (Fig. 7 E). Consistent with this, we found that wortmannin delivery to WT tissue, besides preventing temporal macrophage transitions during the course of repair (as shown in Fig. 7), also resulted in a reduced number of macrophages at late stages after injury ( 6 and 8 d; Fig. S5 F). Together, these results strongly support the idea that MKP-1 loss, through unrestrained p38 activation, promotes persistence of macrophages in a cytokinesilencing state in injured muscle by increasing AKT activation. Thus, defective regeneration of $\mathrm{MKP}-1^{-/-}$mouse muscle might be ascribed, at least in part, to the excessive presence of nonproductive macrophages in damaged tissue, via sustained/enhanced AKT activity.

\section{Discussion}

Unsuccessful repair after tissue damage leads to the derangement of normal structure and loss of function. Here, we demonstrate that dysregulated macrophage transitions, with precocious pro- to antiinflammatory polarization followed by immediate cessation of cytokine expression, impair resolution of tissue damage and efficient repair. From a mechanistic point of view, our study provides evidence for a novel macrophage-specific role for MKP-1 in regulating the evolution as well as the resolution of inflammation during muscle tissue repair by controlling p38-mediated AKT activation. Genetic and pharmacological interference with these signaling pathways also dysregulated inflammation-dependent tissue healing. We found that unrestricted p38 activity induced the expression of miR-21 in MKP-1 ${ }^{-/-}$macrophages, leading to down-regulation of its substrate PTEN, thus inducing AKT activity. This dysregulated inflammatory response underlies the persistence of myofiber damage and impaired growth of regenerating myofibers in mice lacking MKP-1. Importantly, defective muscle regeneration in mice deficient in $\mathrm{MKP}-1$ could be completely restored by $\mathrm{MKP}-1^{+/+}$ $\mathrm{BM}$ transplantation, strongly suggesting dispensability of this phosphatase for satellite cell-dependent myofiber repair. Our conclusions were confirmed by using in vitro satellite cell cultures and single myofiber explants. Satellite cell-intrinsic MKP-1 loss neither affected activation of p38 (a critical regulatory pathway in satellite cell behavior) or myogenesis in any of the models, whereas dysregulated cytokine production in macrophages lacking MKP-1 ${ }^{-1-}$ altered satellite cell functions in a paracrine manner. Interestingly, previous studies had anticipated a relevant function for MKP-1 in myogenesis (Bennett and Tonks, 1997; Wu et al., 2006; Roth et al., 2009; Shi et al., 2010). The distinct findings concerning myogenesis could be explained by the different experimental models used, supporting the need for a future evaluation of MKP-1 function using muscle-specific deletion approaches.

A fundamental unanswered question important for understanding the pathogenesis of inflammation-associated tissue

injury (Inj.), and muscles were isolated at day 8 and 10 postinjury (P.I.) and processed as in Fig. 4 A. IgG was used as a control. An outline of the experiment is depicted. (C, top) Apoptotic F4/80-expressing macrophages were assessed by TUNEL staining. (bottom) CTX-injured gastrocnemius muscle from WT and MKP-1 - - $:$ F480 (red), TUNEL (green), and DAPI (blue). Regenerating fibers are indicated by dotted lines. Apoptotic nuclei are indicated by arrows. (D) Cell proliferation was assessed by Ki-67 staining as in C: Ki-67 (red) and DAPI (blue). (E) Expression of p2 1, p27, and $\beta$-actin (as a loading control) was analyzed by RT-PCR in FACS-isolated macrophage populations at $6 \mathrm{~d}$ after injury as in Fig. $3 \mathrm{~A}$. Means \pm SEM of at least three experiments. $* *, P<0.01$. Bars, $50 \mu \mathrm{m}$. 


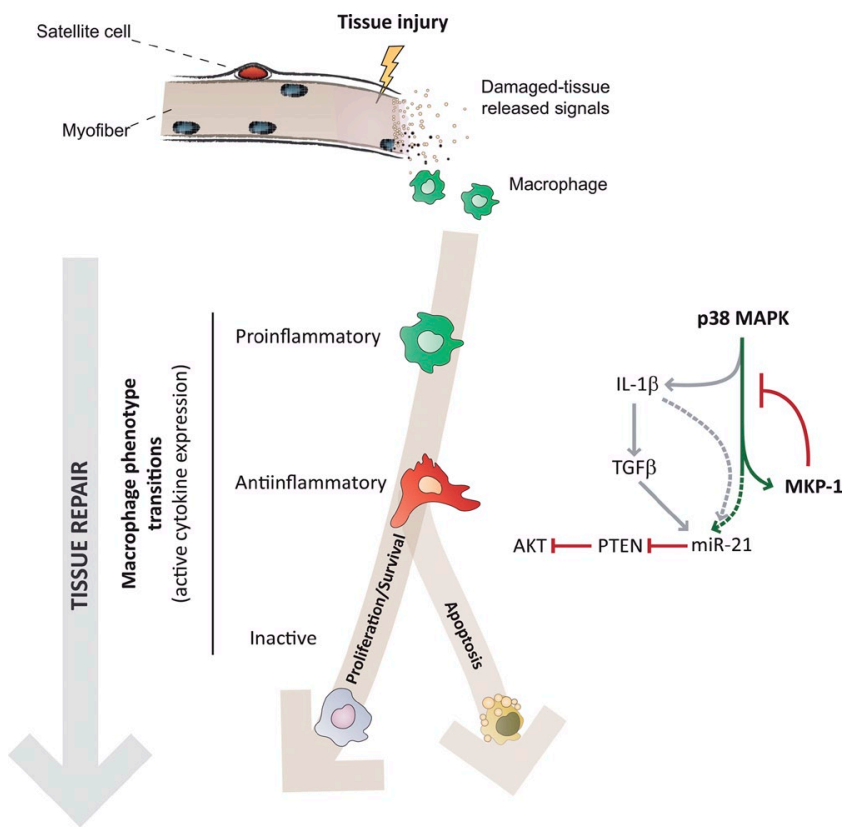

Figure 8. Proposed model for the role of the p38-MKP-1 balance in controlling ordered macrophage transitions during tissue repair.

dysfunction is the nature of the molecular switch that differentiates reparative inflammatory cell functions from pathological inflammatory responses to tissue damage. In addition to the initial pro- to antiinflammatory switch previously described (Arnold et al., 2007), our study identifies a final transit of macrophages from their antiinflammatory activation state to an exhaustion-like state during the inflammation resolution phase, characterized by cessation of both pro- and antiinflammatory cytokine expression. We found that the early pro- to the antiinflammatory macrophage transition, as well as the final progression into a cytokine-silencing state, occurred prematurely in the absence of MKP-1 via unrestricted p38 activation. Thus, we have revealed a novel function of the p38-MKP-1 balance in the resolution of inflammation and tissue repair. Indeed, end-stage macrophages that remain in almost fully recovered muscle retain a certain p38 activation status, whereas their cytokine expression program was silenced. Thus, our data reveal the first molecular determinants of the ordered macrophage inflammatory switches during muscle tissue repair. Consistent with this, the premature delivery of the antiinflammatory cytokine IL-10 to WT muscle shortly after injury during the early proinflammatory phase or, conversely, its premature neutralization (mimicking cytokine silencing at advanced repair stages) had a deleterious impact on tissue recovery. Based on these results, it is tempting to propose that altered inflammatory cell phenotypes could underlie pathologies associated with deficient tissue healing.

Our study demonstrates a functional MKP-1-controlled p38-miR-21-AKT pathway operating at advanced stages of the repair process. That is, this axis regulates macrophage fate over time, such as the acquisition of macrophage antiinflammatory status, apoptosis, and final silencing of the cytokine gene program contributing to the resolution of inflammation. We propose that, as damaged tissue is cleared, macrophage-produced antiinflammatory cytokines shut down the early acute proinflammatory wave, and eventually, when tissue has fully recovered, macrophages undergo apoptosis and/or return to a resting state. Indeed, as growth of regenerating myofibers increased in WT mice, muscle macrophage apoptosis was more pronounced, and unexpectedly, the surviving macrophages ceased the expression of both pro- and antiinflammatory cytokines. In contrast, blunted myofiber growth in the absence of MKP-1 correlated with the increased presence of (prematurely silenced) muscle macrophages, which could be ascribed to attenuated cell apoptosis and enhanced proliferation caused by dysregulation of the PI3K-AKT pathway in these cells. Consistent with this, pharmacological inhibition of AKT was able to perturb normal macrophage cell behavior in injured muscle over time and could also delay cytokine silencing during the resolution of inflammation. Thus, by sequentially controlling macrophage-intrinsic p38-dependent AKT activation, MKP-1 emerges as an important regulator of inflammation-mediated tissue repair beyond sepsis prevention.

Interestingly, it has been described that upon endoplasmic reticulum stress or proapoptotic signals, p38 promotes survival of skin macrophages through direct activation of AKT by MK2 (Seimon et al., 2009). Moreover, the PI3K-AKT pathway negatively regulates MAPKs and proinflammatory gene expression in BM-stimulated macrophages in vitro (Luyendyk et al., 2008). We now propose that $\mathrm{p} 38$, by inducing IL-1 $\beta$ at the early proinflammatory macrophage stage after injury, stimulates TGF $\beta$ expression in antiinflammatory macrophages. Indeed, p38 inhibition at early stages after injury reduces IL- $1 \beta$ expression in proinflammatory cells and affects TGF $\beta$ expression in antiinflammatory muscle macrophages (unpublished data). Macrophage-produced TGF $\beta$, in turn, will further promote miR-21 maturation and subsequent PTEN down-regulation and AKT activation, thereby affecting cytokine gene silencing and macrophage cell number as tissue repair advances. Additionally, we demonstrated that $\mathrm{p} 38$ activation could directly induce miR-21 gene transcription in macrophages (Fig. $6 \mathrm{H}$ ), likely through AP-1 binding sites on the miR-21 promoter (Qi et al., 2009; Roy et al., 2009; Ribas and Lupold, 2010), reinforcing the idea that p38 might promote miR-21 expression in macrophages by direct and indirect mechanisms. Together, our results allow us to draw a model in which p38-MKP-1 and AKT-PTEN pathways act sequentially and interact with each other through crossregulatory feedback mechanisms at different levels (Fig. 8).

The expression of miR-21 was found dysregulated (increased) in MKP-1 ${ }^{-1-}$ macrophages at advanced stages of muscle damage. The function of miR-21 has been classically associated with cancer based on its high expression in most human tumors (Selcuklu et al., 2009), but no role for miR-21 has yet been described either in inflammation or in muscle repair. It is now becoming evident that miR-21 may represent a common feature of pathological cell growth and stress. This is illustrated by its recently reported roles in cardiac and lung remodeling, by virtue of inhibiting different targets, including Smad7, Sprouty 1, or PTEN (Thum et al., 2008; Hatley et al., 2010; Liu et al., 2010), which in turn, can control cell stress responses. We found that during the course of tissue healing, MKP-1 ablation led to p38-dependent up-regulation of miR-21 in macrophages, 
which temporally correlated with reduced PTEN expression levels and increased AKT levels. Therefore, an inflammatory regulatory cascade can be proposed by which, as tissue repair progresses, macrophage p38 activity is controlled by reexpression of MKP-1, resulting in reduced miR-21-driven macrophage survival via PTEN-dependent inhibition of AKT (Fig. 8, model).

PTEN mutations are often found in human cancers (Keniry and Parsons, 2008), and loss of p38 $\alpha$ in vivo enhances tumorigenesis in several mouse cancer models (Ventura et al., 2007; Wagner and Nebreda, 2009). Conversely, miR-21 is emerging as a potent onco-miR (Medina et al., 2010). Thus, in addition to the well-established cancer inflammation link (Grivennikov and Karin, 2010), this study may extend the commonalities between cancer progression and chronic inflammation-associated degenerative diseases. As interference with the individual components of this signaling pathway can be presently accomplished by using small inhibitory molecules (now entering human clinical trials), our study suggests novel, easy to test approaches to attenuate inflammatory degenerative diseases and to enhance stem cell-driven tissue repair, especially in longterm severe inflammatory myopathies.

\section{Materials and methods}

\section{Mice}

Mice carrying a disruption within exon 2 of MKP-1 $\left(\mathrm{MKP}_{-1} 1^{-1-}\right)$ were derived by implantation of heterozygotic $\left({\left.\mathrm{MKP}-1^{+/-}\right)}\right.$C57BL6 embryos into surrogate mothers (a gift by R. Bravo, Bristol-Myers Squibb, Princeton, NJ; Dorfman et al., 1996). All experiments were performed with mice generated from intercrossed heterozygotes. All animal experiments were approved by the Catalan Government Animal Care. For drug treatments, mice were injected intraperitoneally with vehicle or SB203580 (EMD) at a concentration of $5 \mathrm{mg} / \mathrm{kg}$ body weight every second day (Bulavin et al., 2004) or wortmannin (Sigma-Aldrich) at a concentration of $1 \mathrm{mg} / \mathrm{kg}$ body weight at the indicated times. SB203580 and wortmannin selected concentrations were shown to inhibit p38 and AKT activation, respectively (unpublished data).

\section{Induction of muscle regeneration}

Animals were anesthetized with $80 / 10 \mathrm{mg} / \mathrm{kg}$ ketamine/xylazine (intraperitoneally). Regeneration of skeletal muscle was induced by intramuscular injection of $50 \mu$ of $10^{-5}$ M CTX (Latoxan) in the gastrocnemius muscle group of the mice as previously described (Suelves et al., 2007). The experiments were performed in the right hind-limb muscles of mice. Contralateral uninjured muscles were used as a reference. For cytokines, $50 \mathrm{ng}$ IL-10 (Peprotech) was injected in a volume of $50 \mu$ in the injured muscle at the indicated times. For neutralizing antibodies, $25 \mu \mathrm{g}$ anti-IL-10 (R\&D Systems) was injected in a volume of $25 \mu \mathrm{l}$ in the injured muscle at the indicated times. For miR-21 mimic oligonucleotides, $5 \mu \mathrm{g}$ miR-21 mimics (Thermo Fisher Scientific; sequences are based on Sanger miRBase) were injected in the injured muscle at $3 \mathrm{~d}$ after injury, and muscles were analyzed at day 6. Morphological and biochemical examinations were performed on muscles collected at the indicated days after injury.

\section{Muscle laceration model}

Laceration of the tibialis muscle was performed as previously described (Menetrey et al., 1999) with minor modifications. In brief, tibialis muscles were cut at $60 \%$ of the length from their distal insertion, through $75 \%$ of their width and $50 \%$ of their thickness. After controlling the bleeding with cauterization or simple compression, muscles were sutured. The mice were sacrificed at $21 \mathrm{~d}$ after injury, and the muscles were flash frozen in 2-methylbutane precooled in liquid nitrogen and stored at $-80^{\circ} \mathrm{C}$ until histological analysis.

\section{$B M$ transplantation}

BM was performed as previously described (Suelves et al., 2007). In brief, BM cells were obtained by flushing the femurs and tibiae of donor mice with RPMI 1640 medium (Invitrogen) and were transplanted into recipient mice after lethal irradiation ( 9 Gy). The reconstituting cells $(5 \times$ $10^{6}$ cells) were injected intravenously into the tail vein of each recipient mouse within $24 \mathrm{~h}$ after irradiation. The mice were placed in sterile cages and fed with sterile chow until the reconstitution of BM was completed $8 \mathrm{wk}$ after the transplantation. No changes in general health status were noted in the recipient mice. Regeneration of skeletal muscle was induced by intramuscular injection of CTX as described in the Induction of muscle regeneration subheading.

\section{Isolation and culture of primary macrophages}

To generate BM-derived macrophages (BMDMs), BM cells were flushed from the femurs of mice. Cells were differentiated in DME supplemented with $20 \%$ heat-inactivated FCS and 30\% L929 supernatants containing the macrophage-stimulating factor for 5-7 d. Cells were harvested and plated at a density of $2-4 \times 10^{5} / \mathrm{ml}$ in RPMI supplemented with $5 \%$ FBS. At 24$48 \mathrm{~h}$ after replating, cells were stimulated for various times with $10 \mathrm{ng} / \mathrm{ml}$ LPS (Sigma-Aldrich). CM from WT or MKP-1 ${ }^{-1-}$ BMDMs was obtained by stimulating cell cultures for $2 \mathrm{~h}$ with LPS, changing to fresh medium, and leaving it $4 \mathrm{~h}$ before collection. Knockdown (ant-miR-21) and overexpression (mimic) of miR-21 and scrambled control oligonucleotides (Thermo Fisher Scientific) or overexpression of a WT and nonphosphorylatable ATF2 plasmids (WT ATF2 and T69A/T71A ATF2; Akimoto et al., 2005) was performed via electroporation using the mouse macrophage Nucleofector kit (Lonza). When indicated, cells were stimulated with $100 \mathrm{ng} / \mathrm{ml}$ LPS (Sigma-Aldrich), $2 \mu \mathrm{g} / \mathrm{ml}$ actinomycin D (Sigma-Aldrich), $10 \mu \mathrm{g} / \mathrm{ml}$ CHX (Sigma-Aldrich), $30 \mathrm{ng} / \mathrm{ml}$ recombinant IL-1 $\beta$ (R\&D Systems), and $30 \mathrm{ng} / \mathrm{ml}$ of a blocking antibody anti-IL-1 $\beta$ (R\&D Systems). SB203580 was used at $5 \mu \mathrm{M}$.

Retroviral infection was performed with pCLNCX-MKK6E or empty vector packaged in 293T cells with an ecotropic envelope. In brief, the viruses were generated by cotransfection of the plasmids form of $25 \mu \mathrm{g}$ retroviral vectors and $5 \mu \mathrm{g}$ packaging construct (pCLEco) in the 293T cell line by calcium phosphate precipitation. The following day, precipitates were removed, and fresh medium was added. This medium containing the viral particles was recovered $48 \mathrm{~h}$ later and centrifuged at 3,000 $\mathrm{g}$ for $10 \mathrm{~min}$. Cultures were infected by adding to each plate $6 \mathrm{ml}$ medium containing the viral particles, $6 \mathrm{ml}$ medium, $10 \mu$ Hepes $(1 \mathrm{M}), \mathrm{pH} 7.3$, and $4 \mu \mathrm{g}$ polybrene (Sigma-Aldrich) per $\mathrm{ml}$. The medium was removed $24 \mathrm{~h}$ later, and the cells were then cultured as indicated

\section{Isolation of muscle macrophages by FACS}

Hind-limb muscles were collected and weighed. Injured muscle weight reduced steadily with a peak of reduction $(40-50 \%)$ at $6 \mathrm{~d}$ after injury. Muscles were dissociated in DME containing collagenase B $0.2 \%$ (Roche) and $0.2 \%$ trypsin-EDTA at $37^{\circ} \mathrm{C}$ for 45 min twice, filtered, and counted. Cells were separated using a Percoll gradient and stained with FITCconjugated anti-CD45, allophycocyanin-Cy7-conjugated F4/80 and phycoerythrin-conjugated Ly- $6 \mathrm{C}$ antibodies (BD). Cells were sorted using a cell sorter (FACS Aria II; BD). Populations presenting $>90 \%$ purity were used. Cells consisted in a homogeneous monocyte/macrophage population, as indicated by their mononuclearity, read as low orthogonal (side) scatter in the flow cytometer. Total number of cells was normalized by milligram of wet tissue.

\section{Isolation and culture of muscle satellite cells}

Hind-limb muscles from mice were excised, separated from adipose and connective tissue, minced into a coarse slurry, and then digested for $1 \mathrm{~h}$ with $0.1 \%$ pronase (Sigma-Aldrich) in DME at $37^{\circ} \mathrm{C}$ with mild agitation. The digest was then mechanically dissociated by repeated trituration followed by filtration through a 100-um vacuum filter (Millipore). The filtered digest was centrifuged through an isotonic Percoll gradient $160 \%$ overlaid with $20 \%$ ). Mononucleated cells in the Percoll interface were collected and resuspended in Ham's F10 medium supplemented with $20 \%$ FCS, $100 \mathrm{U} / \mathrm{ml}$ penicillin, $100 \mathrm{\mu g} / \mathrm{ml}$ streptomycin, $0.001 \%$ Fungizone, and $5 \mathrm{ng} / \mathrm{ml}$ basic FGF (growth medium [GM]). Primary satellite cell cultures were maintained on a routine basis on collagen-coated dishes in GM. The medium was changed daily, and cultures were passaged $1: 3$ as they reached $60-70 \%$ confluence. Experiments were performed by plating cells on Matrigel Basement Membrane Matrix-coated dishes (BD). To maintain the primary characteristics of the cells, all experiments were performed using cultures that had undergone between four and seven passages. All experiments were performed with independent cell isolates from at least three different animals for each genotype. To induce muscle differentiation and fusion, GM was replaced by differentiation medium (DM; DME supplemented with $2 \%$ horse serum, $2 \mathrm{mM} \mathrm{L-glutamine,} 100 \mathrm{U} / \mathrm{ml}$ penicillin, $100 \mu \mathrm{g} / \mathrm{ml}$ streptomycin, and $0.001 \%$ Fungizone) at satellite cell subconfluence. 


\section{Proliferation, migration, and fusion assays}

For the proliferation assay, satellite cells were cultured for $12 \mathrm{~h}$ in GM, and to detect S-phase cells, cultures were pulsed with BrdU (Sigma-Aldrich) $1 \mathrm{~h}$ before fixation in $3.7 \%$ formaldehyde for $10 \mathrm{~min}$ and were immunostained using anti-BrdU antibody (Oxford Biotech) and a specific secondary biotinylated goat anti-rat antibody (Jackson ImmunoResearch Laboratories, Inc.) followed by quantification (see Perdiguero et al., 2007). Satellite cell migration assays were performed using transwells. Cells were plated on top of a transwell with 8- $\mu \mathrm{m}$ pore membrane (BD), previously coated with Matrigel, and immersed in a well of a 24 -well culture plate with migration medium (DME with $1 \%$ FBS and $0.5 \%$ BSA) for $6 \mathrm{~h}$. After incubation, cells on the upper surface of the membrane were removed using cotton swabs, and the membranes were fixed in 3.7\% formaldehyde for $10 \mathrm{~min}$ and stained with $2 \%$ crystal violet. Stained cells that had migrated and adhered to the transwell membrane were quantified by counting under the microscope (CKX41; Olympus).

For fusion analysis, cells were immunostained with anti-eMHC antibody, and nuclei within the eMHC-positive myofibers were quantified (see Perdiguero et al., 2007). When indicated, CM of WT or MKP1 ${ }^{-1-}$ BMDMs was added.

\section{Histology and immunohistochemistry}

Gastrocnemius and plantaris muscles from WT and $\mathrm{MKP}_{-} 1^{-1-}$ mice were frozen in isopentane cooled with liquid nitrogen and stored at $-80^{\circ} \mathrm{C}$ until analysis. 10- $\mathrm{\mu m}$ sections were collected from the midbelly of muscles and were stained with hematoxylin/eosin (H/E).

Immunohistochemistry on muscle cryosections was performed with the following antibodies: anti-Pax7, anti-Myogenin (F5D), anti-eMHC (F1.652; Developmental Studies Hybridoma Bank), anti-F4/80 (AbD Serotec), antiphospho-p38 (Cell Signaling Technology), antiphospho-c-Jun (Santa Cruz Biotechnology, Inc.), anti-MyoD (5.8A; Dako), and anti$\mathrm{Ki}-67$ (Abcam). Labeling of cryosections with mouse monoclonal primary antibodies was performed using the peroxidase or fluorescein staining kit (Mouse on Mouse; Vector Laboratories) according to the manufacturer's instructions. Double immunostaining was performed with sequential addition of each primary and secondary antibody using appropriate positive and negative controls. Sections were air dried, kept unfixed (Pax7 and eMHC) or fixed on PFA 2-4\%, washed on PBS, and incubated with primary antibodies according to manufacturer's instructions after blocking for $1 \mathrm{~h}$ at room temperature with a high protein-containing solution on PBS (Vector Laboratories). Subsequently, the slides were washed on PBS and incubated with appropriate secondary antibodies and labeling dyes. For immunofluorescence, secondary antibodies were coupled to Alexa Fluor 488 or Alexa Fluor 568 fluorochromes, and nuclei were stained with TO-PRO-3 or DAPI (Invitrogen). After washing, tissue sections were mounted with Vectashield containing DAPI (Vector Laboratories) or Mowiol. TUNEL was performed as indicated by the manufacturer (Roche).

Digital images were acquired using an upright microscope (DMR6000B; Leica) equipped with a camera (DFC300FX; Leica) for immunohistochemical color pictures or a camera (ORCA-ER; Hamamatsu Photonics) for immunofluorescence pictures. HCX PL Fluotar 10x/0.30 $\mathrm{NA}, 20 \times / 0.50 \mathrm{NA}$, and 40×/0.75 NA objectives were used. Acquisition was performed using LAS AF software (Leica). Images were composed and edited in Photoshop CS5 (Adobe), in which background was reduced using brightness and contrast adjustments applied to the whole image. Individual fibers were outlined, and their CSA was determined with the public domain image analysis software ImageJ (National Institutes of Health).

\section{In situ hybridization of miR-21}

In situ hybridizations were performed in 10-pm cryosections from gastrocnemius muscles using antisense locked nucleic acid (LNA)modified oligonucleotides. LNA/DNA oligonucleotides contained LNAs at eight consecutive centrally located bases and had the following sequences: LNA-miR-21, 5'-TCAACATCAGTCTGATAAGCTA-3', and LNA-scrambled, 5'-CATTAATGTCGGACAACTCAAT-3'. In brief, the sections were dried at room temperature, followed by fixation in $4 \%$ paraformaldehyde, and followed by treatment with $10 \mathrm{\mu g} / \mathrm{ml}$ proteinase $K$. Sections were then blocked with hybridization solution and incubated with FITC-conjugated miR-2 1 probes or FITC-conjugated control probes (Eurogentec) with scrambled sequence (Eurogentec). The sections were washed with $0.2 \times$ SSC followed by incubation with HRPconjugated anti-FITC antibody (Roche) overnight. Nuclei were counterstained with hematoxylin.
RNA isolation, RT-PCR, and quantitative real-time PCR (qPCR)

Total RNA was isolated from macrophages or primary myoblasts using TriPure reagent (Roche) or miRNeasy Mini Kit (QIAGEN) and analyzed by RT-PCR or qPCR. RT-PCR primers used in this study were as follows: TNF, 5'-TTCCAGATTCTTCCCTGAGGT-3' and 5'-TAAGCAAAAGAGGAGGCAACA-3'; IL-1 $\beta$, 5'-TGACGTTCCCATTAGACAACTG-3' and 5'-CCGTCTTTCATTACACAGGACA-3'; IL-10, 5'-ACCAGCTGGACAACATACTGC-3' and 5'-TCACTCTTCACCTGCTCCACT-3'; TGF $\beta$, 5'-GAGACGGAATACAGGGCTTIC-3' and 5'-TCTCTGTGGAGCTGAAGCAAT-3'; PTEN, 5'-CATCTCTCTCCTCCTTTTTCTTCA-3' and 5'-CAAACATCATCTTGTGAAACAGC-3'; MKP-1, 5'-TGGAGATCCTGTCCTTCCTG-3' and 5'-AAGCTGAAGTTCGGGGAGAT-3'; p2 1, 5'-GTCCAATCCTGGTGATGTCC-3' and 5'-CAGGGTTTTCTCTTGCAGAAG-3'; p27, 5'-CAAACGTGAGAGTGTCTAACG-3' and 5'-CGTCTGGCGTCGAAGGC-3'; IL4R, 5'-TGTAGCCCGGCCCCAAATCC-3' and 5'-GGCGGCACCCTGCTTCACTG-3'; Arg 1, 5'-GAAGAATGGAAGAGTCAGTGTGGTG-3' and 5'-GAGGAGAAGGCGTTTGCTTAGC-3'; HMGB 1, 5'-CGCGGAGGAAAATCAACTAA-3' and 5'-GCAGACATGGTCTTCCACCT-3'; CD14, 5'-CAGGTCCGCGTCTTCCCTGC-3' and 5'-AGCACGCTGAGCTTGGCTGG-3'; CD16, 5'-TCTGTGCGGAGGGGTCTTCA-3' and 5'-AGGGTAGCTGCGTGCGCATT-3'; and $\beta$-actin, 5'-CACCTTCTACAATGAGCT-3' and 5'-GAAGGTAGTCTGTCAGGTCCC-3' .

For qPCR experiments, DNase digestion of $10 \mu \mathrm{g}$ RNA was performed using $2 \cup$ DNase (TURBO DNA-free; Invitrogen). cDNA was synthesized from $2 \mu \mathrm{g}$ total RNA using the First-Strand cDNA Synthesis kit (GE Healthcare). For qPCR, reactions were performed on a LightCycler 480 System using a LightCycler 480 SYBR Green I Master (Roche) and specific primers. Thermocycling conditions were as follows: initial step of $10 \mathrm{~min}$ at $95^{\circ} \mathrm{C}$ and then 50 cycles of 15 -s denaturation at $94^{\circ} \mathrm{C}, 10$-s annealing at $60^{\circ} \mathrm{C}$, and 15 -s extension at $72^{\circ} \mathrm{C}$. Reactions were run in triplicate, and automatically detected threshold cycle values were compared between samples. Transcripts of the ribosomal protein $\mathrm{L} 7$ gene were used as an endogenous control, with each unknown sample normalized to L7 content. qPCRs primers used in this study were as follows: MyoD, 5'-GCCGCCTGAGCAAAGTGAATG-3' and 5'-CAGCGGTCCAGTGCGTAGAAG-3'; Myogenin, 5'-GGTGTGTAAGAGGAAGTCTGTG-3' and 5'-TAGGCGCTCAATGTACTGGAT-3'; MCK， 5'-AGGCATGGCCCGAGAC-3' and 5'-AGATCACGCGAAGGTGGTC-3'; MHC-2× 5'-CTCCAGGCTGCTTTAGAGGAA-3' and 5'-CCTGCTCCTAATCTCAGCATCC-3'; p21, 5'-CCAGGCCAAGATGGTGTCTT-3' and 5'-TGAGAAAGGATCAGCCATTGC-3'; TNF, 5'-CGCTCTTCTGTCTACTGAACTT-3' and 5'-GATGAGAGGGAGGCCATT-3'; IL-1 $\beta, 5^{\prime}$-CCAAAATACCTGTGGCCTTGG-3' and 5'-GCTTGTGCTCTGCTTGTGAG-3'; IL-10, 5'-GTGGAGCAGGTGAAGAGTGA-3' and 5'-CGAGGTITCCAAGGAGTT-3'; IL-6, 5'-GAGGATACCACTCCCAACAGACC-3' and 5'-AAGTGCATCATCGTGTTCATACA-3'; TGF $\beta$, 5'-CTCCACCTGCAAGACCAT-3' and 5'-CTTAGTTTGGACAGGATCTGG-3'; and L7, 5'-GAAGCTCATCTATGAGAAGGC-3' and 5'-AAGACGAAGGAGCTGCAGAAC-3'.

For detection of mature miRNA, the TaqMan MicroRNA assay kit (Applied Biosystems) was used according to the manufacturer's instructions. A mean of three experiments each performed in triplicate with standard errors is presented.

\section{Western blotting}

Preparation of cell lysates and Western blotting were performed as previously described in Perdiguero et al. (2007). In brief, cell lysates were prepared with immunoprecipitation buffer $150 \mathrm{mM}$ Tris $\mathrm{HCl}, \mathrm{pH} 7.5,150 \mathrm{mM}$ $\mathrm{NaCl}, 1 \% \mathrm{NP}-40,5 \mathrm{mM}$ EGTA, $5 \mathrm{mM}$ EDTA, $20 \mathrm{mM} \mathrm{NaF}$, and $25 \mathrm{mM}$ $\beta$-glycerophosphate) supplemented with protease and phosphatase inhibitors (Complete Mini [Roche]; phosphatase inhibitor cocktail [Sigma-Aldrich]). Cleared lysates containing $\sim 50 \mu \mathrm{g}$ protein were separated by SDS-PAGE and transferred to nitrocellulose membranes. Antibodies used were p38 C-20, JNK-1 C-17, MKP-1 M-1 8 (Santa Cruz Biotechnology, Inc.), phospho-p38, phospho-ATF2, phospho-AKT, AKT (Cell Signaling Technology), and $\alpha$-tubulin (Sigma-Aldrich).

\section{Statistical analysis}

Prism software (GraphPad Software) was used for all statistical analyses. Results from corresponding time points of each group were averaged and used to calculate descriptive statistics. One-way analysis of variance and Tukey posthoc test or a Kruskall Wallis and Dunn's posthoc test was used on multiple comparisons and all possible pairwise comparisons among groups at each time point. Data are means \pm SEM. Significance was accepted at $P<0.05$.

\section{Online supplemental material}

Fig. $\mathrm{S} 1$ shows $\mathrm{F} 4 / 80^{+}$cell numbers and representative pictures, phosphop38/c-Jun immunohistochemistry, in vitro p38 activity data, and representative pictures of $\mathrm{H} / \mathrm{E}$ staining of injured muscles after CTX injection. 
Fig. S2 shows laceration pictures, basal Pax7 and CSA numbers, single fiber experiments, and muscle-intrinsic in vitro paradigms, which demonstrate the dispensability of MKP-1. Fig. S3 shows macrophage CM experiments and FACS gating scheme and profiles. Fig. S4 contains extra RT-PCR profiles, in vitro data on endotoxin-stimulated macrophages, and representative pictures of AKT activation in vivo. Fig. S5 contains qPCR controls from wortmannin treatments and miR-21 expression, AKT activity, and number of cells after interference of miR-21-AKT in vivo and in vitro. Online supplemental material is available at http://www.jcb .org/cgi/content/full/jcb.201104053/DC1.

We thank Dr. R. Bravo for the MKP-1 ${ }^{-1-}$ mice; S. Gutarra, V. Lukesova, and C. Mann for helpful discussions and technical help; Dr. J. Martín-Caballero for assistance in animal experimentation; and Dr. O. Fornas for assistance in FACS analysis.

The authors acknowledge funding from The Ministry of Science and Innovation (PLE2009-0124, SAF2009-09782, FIS-PS09/01267, and SAF2010-216821, Association Française contre les Myopathies, Fundación Marató-TV3/R-Pascual, Muscular Dystrophy Association, and European Union Seventh Framework Programme (Myoage, Optistem, and Endostem). P. Sousa-Victor was supported by a predoctoral fellowship from Fundação para a Ciência e a Tecnologia.

Submitted: 11 April 2011

Accepted: 13 September 2011

\section{References}

Akimoto, T., S.C. Pohnert, P. Li, M. Zhang, C. Gumbs, P.B. Rosenberg, R.S. Williams, and Z. Yan. 2005. Exercise stimulates Pgc-1alpha transcription in skeletal muscle through activation of the p38 MAPK pathway. J. Biol. Chem. 280:19587-19593. http://dx.doi.org/10.1074/jbc .M408862200

Arnold, L., A. Henry, F. Poron, Y. Baba-Amer, N. van Rooijen, A. Plonquet, R.K. Gherardi, and B. Chazaud. 2007. Inflammatory monocytes recruited after skeletal muscle injury switch into antiinflammatory macrophages to support myogenesis. J. Exp. Med. 204:1057-1069. http://dx.doi.org/10.1084/ jem. 20070075

Bennett, A.M., and N.K. Tonks. 1997. Regulation of distinct stages of skeletal muscle differentiation by mitogen-activated protein kinases. Science. 278:1288-1291. http://dx.doi.org/10.1126/science.278.5341.1288

Bianchi, M.E., and A.A. Manfredi. 2007. High-mobility group box 1 (HMGB1) protein at the crossroads between innate and adaptive immunity. Immunol. Rev. 220:35-46. http://dx.doi.org/10.1111/j.1600065X.2007.00574.x

Bulavin, D.V., C. Phillips, B. Nannenga, O. Timofeev, L.A. Donehower, C.W. Anderson, E. Appella, and A.J. Fornace Jr. 2004. Inactivation of the Wip1 phosphatase inhibits mammary tumorigenesis through p38 MAPKmediated activation of the p16(Ink4a)-p19(Arf) pathway. Nat. Genet. 36:343-350. http://dx.doi.org/10.1038/ng1317

Chi, H., S.P. Barry, R.J. Roth, J.J. Wu, E.A. Jones, A.M. Bennett, and R.A. Flavell. 2006. Dynamic regulation of pro- and anti-inflammatory cytokines by MAPK phosphatase 1 (MKP-1) in innate immune responses. Proc. Natl. Acad. Sci. USA. 103:2274-2279. http://dx.doi.org/10.1073/ pnas. 0510965103

Coulthard, L.R., D.E. White, D.L. Jones, M.F. McDermott, and S.A. Burchill. 2009. p38(MAPK): stress responses from molecular mechanisms to therapeutics. Trends Mol. Med. 15:369-379. http://dx.doi .org/10.1016/j.molmed.2009.06.005

Cuenda, A., G. Alonso, N. Morrice, M. Jones, R. Meier, P. Cohen, and A.R. Nebreda. 1996. Purification and cDNA cloning of SAPKK3, the major activator of RK/p38 in stress- and cytokine-stimulated monocytes and epithelial cells. EMBO J. 15:4156-4164.

Dorfman, K., D. Carrasco, M. Gruda, C. Ryan, S.A. Lira, and R. Bravo. 1996. Disruption of the erp/mkp-1 gene does not affect mouse development: normal MAP kinase activity in ERP/MKP-1-deficient fibroblasts. Oncogene. 13:925-931.

Eming, S.A., M. Hammerschmidt, T. Krieg, and A. Roers. 2009. Interrelation of immunity and tissue repair or regeneration. Semin. Cell Dev. Biol. 20: 517-527. http://dx.doi.org/10.1016/j.semcdb.2009.04.009

Fukata, M., A.S. Vamadevan, and M.T. Abreu. 2009. Toll-like receptors (TLRs) and Nod-like receptors (NLRs) in inflammatory disorders. Semin. Immunol. 21:242-253. http://dx.doi.org/10.1016/j.smim.2009.06.005

Grivennikov, S.I., and M. Karin. 2010. Inflammation and oncogenesis: a vicious connection. Curr. Opin. Genet. Dev. 20:65-71. http://dx.doi.org/10.1016/ j.gde.2009.11.004
Guha, M., and N. Mackman. 2002. The phosphatidylinositol 3-kinase-Akt pathway limits lipopolysaccharide activation of signaling pathways and expression of inflammatory mediators in human monocytic cells. J. Biol. Chem. 277:32124-32132. http://dx.doi.org/10.1074/jbc.M203298200

Gurtner, G.C., S. Werner, Y. Barrandon, and M.T. Longaker. 2008. Wound repair and regeneration. Nature. 453:314-321. http://dx.doi.org/10.1038/ nature 07039

Hammer, M., J. Mages, H. Dietrich, A. Servatius, N. Howells, A.C. Cato, and R. Lang. 2006. Dual specificity phosphatase 1 (DUSP1) regulates a subset of LPS-induced genes and protects mice from lethal endotoxin shock. J. Exp. Med. 203:15-20. http://dx.doi.org/10.1084/jem.20051753

Hatley, M.E., D.M. Patrick, M.R. Garcia, J.A. Richardson, R. Bassel-Duby, E. van Rooij, and E.N. Olson. 2010. Modulation of K-Ras-dependent lung tumorigenesis by MicroRNA-21. Cancer Cell. 18:282-293. http://dx.doi .org/10.1016/j.ccr.2010.08.013

Keniry, M., and R. Parsons. 2008. The role of PTEN signaling perturbations in cancer and in targeted therapy. Oncogene. 27:5477-5485. http://dx.doi .org/10.1038/onc.2008.248

Kim, C., Y. Sano, K. Todorova, B.A. Carlson, L. Arpa, A. Celada, T. Lawrence, K. Otsu, J.L. Brissette, J.S. Arthur, and J.M. Park. 2008. The kinase p38 alpha serves cell type-specific inflammatory functions in skin injury and coordinates pro- and anti-inflammatory gene expression. Nat. Immunol. 9:1019-1027. http://dx.doi.org/10.1038/ni.1640

Kokkola, R., A. Andersson, G. Mullins, T. Ostberg, C.J. Treutiger, B. Arnold, P. Nawroth, U. Andersson, R.A. Harris, and H.E. Harris. 2005. RAGE is the major receptor for the proinflammatory activity of HMGB1 in rodent macrophages. Scand. J. Immunol. 61:1-9. http://dx.doi.org/10.1111/ j.0300-9475.2005.01534.x

Li, J., M. Gorospe, D. Hutter, J. Barnes, S.M. Keyse, and Y. Liu. 2001. Transcriptional induction of MKP-1 in response to stress is associated with histone H3 phosphorylation-acetylation. Mol. Cell. Biol. 21:82138224. http://dx.doi.org/10.1128/MCB.21.23.8213-8224.2001

Li, L., S.F. Chen, and Y. Liu. 2009. MAP kinase phosphatase-1, a critical negative regulator of the innate immune response. Int. J. Clin. Exp. Med. 2: 48-67.

Liu, G., A. Friggeri, Y. Yang, J. Milosevic, Q. Ding, V.J. Thannickal, N. Kaminski, and E. Abraham. 2010. miR-21 mediates fibrogenic activation of pulmonary fibroblasts and lung fibrosis. J. Exp. Med. 207:1589-1597. http://dx.doi.org/10.1084/jem.20100035

Luyendyk, J.P., G.A. Schabbauer, M. Tencati, T. Holscher, R. Pawlinski, and N. Mackman. 2008. Genetic analysis of the role of the PI3K-Akt pathway in lipopolysaccharide-induced cytokine and tissue factor gene expression in monocytes/macrophages. J. Immunol. 180:4218-4226.

Medina, P.P., M. Nolde, and F.J. Slack. 2010. OncomiR addiction in an in vivo model of microRNA-21-induced pre-B-cell lymphoma. Nature. 467:8690. http://dx.doi.org/10.1038/nature09284

Menetrey, J., C. Kasemkijwattana, F.H. Fu, M.S. Moreland, and J. Huard. 1999. Suturing versus immobilization of a muscle laceration. A morphological and functional study in a mouse model. Am. J. Sports Med. 27:222-229.

Meng, F., R. Henson, H. Wehbe-Janek, K. Ghoshal, S.T. Jacob, and T. Patel. 2007. MicroRNA-21 regulates expression of the PTEN tumor suppressor gene in human hepatocellular cancer. Gastroenterology. 133:647-658. http://dx.doi.org/10.1053/j.gastro.2007.05.022

Perdiguero, E., V. Ruiz-Bonilla, L. Gresh, L. Hui, E. Ballestar, P. Sousa-Victor, B. Baeza-Raja, M. Jardí, A. Bosch-Comas, M. Esteller, et al. 2007. Genetic analysis of $\mathrm{p} 38$ MAP kinases in myogenesis: fundamental role of p38alpha in abrogating myoblast proliferation. EMBO J. 26:1245-1256. http://dx.doi.org/10.1038/sj.emboj.7601587

Qi, L., J. Bart, L.P. Tan, I. Platteel, T. Sluis, S. Huitema, G. Harms, L. Fu, H. Hollema, and A. Berg. 2009. Expression of miR-21 and its targets (PTEN, PDCD4, TM1) in flat epithelial atypia of the breast in relation to ductal carcinoma in situ and invasive carcinoma. BMC Cancer. 9:163. http://dx.doi.org/10.1186/1471-2407-9-163

Ribas, J., and S.E. Lupold. 2010. The transcriptional regulation of miR-21, its multiple transcripts, and their implication in prostate cancer. Cell Cycle. 9:923-929. http://dx.doi.org/10.4161/cc.9.5.10930

Roth, R.J., A.M. Le, L. Zhang, M. Kahn, V.T. Samuel, G.I. Shulman, and A.M. Bennett. 2009. MAPK phosphatase-1 facilitates the loss of oxidative myofibers associated with obesity in mice. J. Clin. Invest. 119:38173829. http://dx.doi.org/10.1172/JCI39054

Roy, S., S. Khanna, S.R. Hussain, S. Biswas, A. Azad, C. Rink, S. Gnyawali, S. Shilo, G.J. Nuovo, and C.K. Sen. 2009. MicroRNA expression in response to murine myocardial infarction: miR-21 regulates fibroblast metalloprotease-2 via phosphatase and tensin homologue. Cardiovasc. Res. 82:21-29. http://dx.doi.org/10.1093/cvr/cvp015

Ruffell, D., F. Mourkioti, A. Gambardella, P. Kirstetter, R.G. Lopez, N. Rosenthal, and C. Nerlov. 2009. A CREB-C/EBPbeta cascade induces M2 macrophage-specific gene expression and promotes muscle injury repair. 
Proc. Natl. Acad. Sci. USA. 106:17475-17480. http://dx.doi.org/10.1073/ pnas.0908641106

Seimon, T.A., Y. Wang, S. Han, T. Senokuchi, D.M. Schrijvers, G. Kuriakose, A.R. Tall, and I.A. Tabas. 2009. Macrophage deficiency of p38alpha MAPK promotes apoptosis and plaque necrosis in advanced atherosclerotic lesions in mice. J. Clin. Invest. 119:886-898.

Selcuklu, S.D., M.T. Donoghue, and C. Spillane. 2009. miR-21 as a key regulator of oncogenic processes. Biochem. Soc. Trans. 37:918-925. http:// dx.doi.org/10.1042/BST0370918

Sheedy, F.J., E. Palsson-McDermott, E.J. Hennessy, C. Martin, J.J. O’Leary, Q. Ruan, D.S. Johnson, Y. Chen, and L.A. O'Neill. 2010. Negative regulation of TLR4 via targeting of the proinflammatory tumor suppressor PDCD4 by the microRNA miR-21. Nat. Immunol. 11:141-147. http:// dx.doi.org/10.1038/ni.1828

Shi, H., E. Boadu, F. Mercan, A.M. Le, R.J. Flach, L. Zhang, K.J. Tyner, B.B. Olwin, and A.M. Bennett. 2010. MAP kinase phosphatase-1 deficiency impairs skeletal muscle regeneration and exacerbates muscular dystrophy. FASEB J. 24:2985-2997. http://dx.doi.org/10.1096/fj.09-150045

Soehnlein, O., and L. Lindbom. 2010. Phagocyte partnership during the onset and resolution of inflammation. Nat. Rev. Immunol. 10:427-439. http:// dx.doi.org/10.1038/nri2779

Suelves, M., B. Vidal, A.L. Serrano, M. Tjwa, J. Roma, R. López-Alemany, A. Luttun, M.M. de Lagrán, A. Díaz-Ramos, M. Jardí, et al. 2007. uPA deficiency exacerbates muscular dystrophy in MDX mice. J. Cell Biol. 178:1039-1051. http://dx.doi.org/10.1083/jcb.200705127

Thum, T., C. Gross, J. Fiedler, T. Fischer, S. Kissler, M. Bussen, P. Galuppo, S. Just, W. Rottbauer, S. Frantz, et al. 2008. MicroRNA-21 contributes to myocardial disease by stimulating MAP kinase signalling in fibroblasts. Nature. 456:980-984. http://dx.doi.org/10.1038/nature07511

Tidball, J.G. 2005. Inflammatory processes in muscle injury and repair. Am. J. Physiol. Regul. Integr. Comp. Physiol. 288:R345-R353. http://dx.doi .org/10.1152/ajpregu.00454.2004

Ventura, J.J., S. Tenbaum, E. Perdiguero, M. Huth, C. Guerra, M. Barbacid, M. Pasparakis, and A.R. Nebreda. 2007. p38alpha MAP kinase is essential in lung stem and progenitor cell proliferation and differentiation. Nat. Genet. 39:750-758. http://dx.doi.org/10.1038/ng2037

Vidal, B., A.L. Serrano, M. Tjwa, M. Suelves, E. Ardite, R. De Mori, B. BaezaRaja, M. Martínez de Lagrán, P. Lafuste, V. Ruiz-Bonilla, et al. 2008. Fibrinogen drives dystrophic muscle fibrosis via a TGFbeta/alternative macrophage activation pathway. Genes Dev. 22:1747-1752. http://dx.doi .org/10.1101/gad.465908

Villalta, S.A., H.X. Nguyen, B. Deng, T. Gotoh, and J.G. Tidball. 2009. Shifts in macrophage phenotypes and macrophage competition for arginine metabolism affect the severity of muscle pathology in muscular dystrophy. Hum. Mol. Genet. 18:482-496. http://dx.doi.org/10.1093/hmg/ddn376

Wagner, E.F., and A.R. Nebreda. 2009. Signal integration by JNK and p38 MAPK pathways in cancer development. Nat. Rev. Cancer. 9:537-549. http://dx.doi.org/10.1038/nrc2694

Wang, X., and Y.Liu. 2007. Regulation of innate immune response by MAP kinase phosphatase-1. Cell. Signal. 19:1372-1382. http://dx.doi.org/10.1016/j .cellsig.2007.03.013

Wu, J.J., R.J. Roth, E.J. Anderson, E.G. Hong, M.K. Lee, C.S. Choi, P.D. Neufer, G.I. Shulman, J.K. Kim, and A.M. Bennett. 2006. Mice lacking MAP kinase phosphatase-1 have enhanced MAP kinase activity and resistance to diet-induced obesity. Cell Metab. 4:61-73. http://dx.doi .org/10.1016/j.cmet.2006.05.010

Zhang, X., and D.M. Mosser. 2008. Macrophage activation by endogenous danger signals. J. Pathol. 214:161-178. http://dx.doi.org/10.1002/path.2284

Zhao, Q., X. Wang, L.D. Nelin, Y. Yao, R. Matta, M.E. Manson, R.S. Baliga, X. Meng, C.V. Smith, J.A. Bauer, et al. 2006. MAP kinase phosphatase 1 controls innate immune responses and suppresses endotoxic shock. J. Exp. Med. 203:131-140. http://dx.doi.org/10.1084/jem.20051794 